NASA Technical Memorandum 103632

\title{
Intercalated Graphite Fiber Composites as EMI Shields in Aerospace Structures
}

James R. Gaier

Lewis Research Center

Cleveland, Ohio

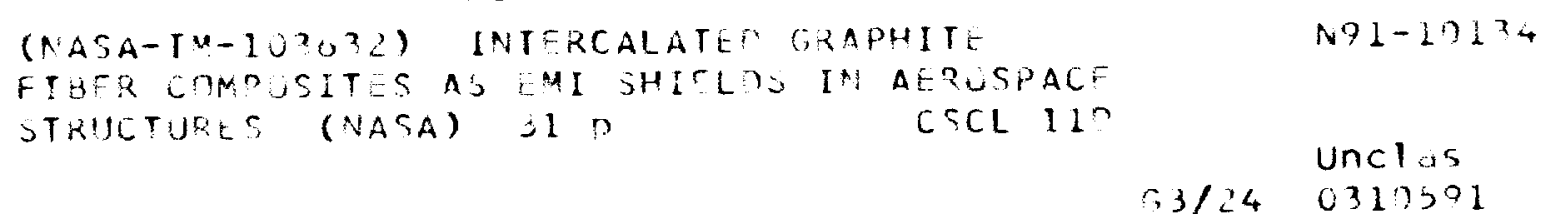

Prepared for the International Symposium on Carbon, 1990 sponsored by the Carbon Society of Japan Tsukubo, Japan, November 4-8, 1990 


\title{
INTERCALATED GRAPHITE FIBER COMPOSITES AS EMI SHIELDS IN AEROSPACE STRUCTURES
}

\author{
James R. Gaier \\ NASA Lewis Research Center \\ Cleveland, Ohio 44135, USA
}

\begin{abstract}
The requirements for electro-magnetic interference (EMI) shielding in aerospace structures are complicated over that of ground structures by their weight limitations. As a result, the best EMI shielding materials must blend low density, high strength, and high elastic modulus with high shielding ability. In addition, fabrication considerations including penetrations and joints play a major role. The EMI shielding characteristics are calculated for shields formed from pristine and intercalated graphite fiber / epoxy composites and compared to preliminary experimental results and to shields made from aluminum. Calculations indicate that EMI shields could be fabricated from intercalated graphite composites which would have less than 12 percent of the mass of conventional aluminum shields, based on mechanical properties and shielding characteristics alone.
\end{abstract}

\section{INTRODUCTION}

Of all of the potential applications which utilize the electrical properties of graphite intercalation compounds none has drawn as much attention as electro-magnetic interference (EMI) shielding. The driving force has been idea of light-weight shielding for spacecraft, aircraft, and automobiles.

With increased reliance on electronic controls, EMI shielding requirements are becoming ever more important. Present technology uses metallic shielding boxes to provide this function. In commercial communications satellites saving a small amount in the structure can enable an additional channel, or enough fuel to extend the lifetime by months or years. In aircraft and automobiles weight savings would translate directly into increased fuel efficiency and longer range. Weights could be dramatically reduced by replacing metallic components, with densities ranging from $2.7-8.9 \mathrm{~g} / \mathrm{cm}^{3}$, with composites with densities of about $1.8 \mathrm{~g} / \mathrm{cm}^{3}$.

Typically 15 to 20 percent of the mass of the power and electronics systems of a typical satellite resides in the EMI shielding cover boxes. Additionally, about half of the mass of the electronics system is in the supporting structure, including the shielding boxes. Thus a significant weight savings in the shielding would result in significant weight saving of the power system. 
The limit to mass reduction in present shielding is not its shielding ability, but its mechanical characteristics, such as its strength and stiffness. Metal foils may have sufficient shielding capability, but do not have sufficient structural integrity to build spacecraft components. Foil shielding boxes would collapse under handling loads and launch stresses. The intrinsic shielding, therefore, does not have to be as high as that of metals such as aluminum, but merely sufficient to meet the shielding requirements.

Carbon fiber composites have been used successfully to reduce aircraft and spacecraft weight in structural components. For example, a shielding box single ply of $0-90^{\circ}$ carbon fiber/epoxy would have less than 12 percent of the mass of a standard $80 \mathrm{mil}(2.0 \mathrm{~mm})$ aluminum shielding box. Unfortunately, conventional carbon fiber/epoxy composites are not sufficiently conductive to provide adequate shielding. Foils, paints and platings on such composites can be used, but there are reliability problems caused by poor scratch resistance, poor adhesion, and oxidation.

Another possible solution to making composites electrically conducting is to use composites of intercalated graphite fibers. Intercalation is the process of introducing guest atoms or molecules between the graphene layers of graphite (fig. 1). The guest species can contribute carriers (either electrons or electron holes) to the graphite lattice, and thus increase its conductivity significantly ${ }^{1}$ without seriously degrading its mechanical properties. ${ }^{2}$ Although most intercalation compounds are unstable in air and at even the moderate temperatures needed to cure epoxy resins, the residual intercalation compounds which use bromine as the guest molecule have been shown to be quite stable. ${ }^{3}$ Laminar composites have also been made from the bromine intercalated fibers which show enhanced electrical conductivity. ${ }^{4}$ The purpose of this study was to assess whether intercalated graphite composites would have sufficient shielding ability to make them an attractive alternative EMI shielding material.

\section{EMI Shielding Fundamentals}

EMI will be defined as any electro-magnetic radiation, periodic or random, that has a disturbing influence on devices exposed to it. In this definition conductive interference, that is, disturbances which travel along the power or grounding paths, is purposefully excluded, since the shielding from such disturbances involves the installation of active devices (such as isolation transformers) rather than passive materials. Thus, for this discussion we are only interested in radiation which is propagated through space.

The discussion and equations that follow have been adapted from a NASA special publication by Taylor, though there are several other sources available. ${ }^{5}$ An inherent assumption about these equations is that the conductivity of the shielding material is isotropic. It is recognized that this assumption is not valid for highly conducting fibers embedded in an insulating matrix, but yet it will still be used to gain a first approximation of the EMI shielding ability of these materials.

There are two principal modes of EMI, near field and far field interference. In the near field the interference may be dominated by either the electrical or the magnetic 
component of the electro-magnetic wave, and in the far field the wave characteristics are determined by the permittivity and permeability of free space, and so the components are equal. A convenient way to describe the three modes is in terms of the characteristic wave impedance $\left(\mathrm{Z}_{\mathrm{o}}\right)$ which is generally defined as the ratio of the electric component to the magnetic component $(\mathbf{E} / \mathbf{H})$. Thus, the characteristic impedance of an electro-magnetic wave, when measured in vacuum far from its source (far field) is

$$
Z_{o}=\left(\mu_{o} / \epsilon_{o}\right)^{1 / 2}=377 \Omega
$$

where $\epsilon_{\mathrm{o}}$ is the permittivity of free space $\left(8.85 \times 10^{-12} \mathrm{~F} / \mathrm{m}\right)$ and $\mu_{\mathrm{o}}$ is the permeability of free space $\left(1.26 \times 10^{-6} \mathrm{H} / \mathrm{m}\right)$. Interference generated in the far field is said to be radiative coupled.

When the distance from the source (r) is small with respect to the wavelength (near field) the electrical component of the impedance, $Z_{e}$, is approximated by

$$
Z_{e}=1 / w \epsilon_{0} r
$$

where " $w$ " is the angular frequency of the incident wave $(2 \pi f)$ and " $\mathrm{f}$ " is its frequency. If the near field noise is from a relatively high-voltage, low-current source it will be dominated by the electric field component of the wave. Such interference is capacitively coupled between the source and the device.

The magnetic component of the impedance, $Z_{h}$, is similarly approximated by

$$
\mathrm{Z}_{\mathrm{h}}=w \mu_{\mathrm{o}} \mathrm{r} \text {. }
$$

If the near field noise is generated from a relatively high-current, low-voltage source the magnetic component will dominate and there will be inductive coupling between the source and the device.

There are three additive components to EMI shielding. The total attenuation of a shield (S) is the sum of the terms,

$$
S=A+R+B .
$$

where "A" is the absorption, " $\mathrm{R}$ " is the reflection, and "B" is the result of multiple internal reflections within the shield. This is illustrated in figure 2 . The shielding can be dominated either by the absorptive term or by the reflective term. Generally, reflection tends to dominate at low frequency and absorption at high frequency. If reflection dominates in a shield that contains a noisy source, there is the potential of self interference. If absorption dominates in the shielding of a strong source the absorbed energy, which is converted into heat, may need to be dissipated in a controlled way (heat-sinking, radiator, etc.).

Attenuation must be measured over several orders of magnitude, and so is conveniently expressed in units of decibels $(\mathrm{dB})$ which is defined as 


$$
\mathrm{dB}=10 \log _{10}(\mathrm{Po} / \mathrm{P})
$$

where $\mathrm{P}_{\mathrm{o}}$ and $\mathrm{P}$ are the initial and final power densities of the electro-magnetic wave in $\mathrm{W} / \mathrm{m}^{2}$ respectively. Alternately is can be expressed as

$$
\mathrm{dB}=20 \log _{10}\left(\mathrm{E}_{\mathrm{o}} / \mathrm{E}\right)
$$

where $E_{o}$ and $E$ are the initial and final root mean square electric field strengths of the electro-magnetic wave in $\mathrm{V} / \mathrm{m}$ respectively.

The absorption term is the same whether the source is in the near or far field, and whether it is dominated by the electric or magnetic fields. It increases with thickness, conductivity, permeability, and frequency and follows the form

$$
\mathrm{A}=\left(9.88 \times 10^{5}\left(\mathrm{sec} / \mathrm{m}^{\natural}\right)^{1 / 2}\right) \mathrm{t}(\mu \mathrm{f} \sigma)^{1 / 2}
$$

where "A" is the absorptive attenuation in $\mathrm{dB}$, " $\mathrm{t}$ " is the thickness of the shield in meters, " $\mu$ " is the permeability relative to that of free space, " $\mathrm{f}$ " is the frequency of the radiation, and $" \sigma "$ is the conductivity of the shield in $\mathrm{S} / \mathrm{cm}$. It has the form of a simple exponential as shown in figure 3 . When discussing absorption the skin depth $(\delta)$ is often used. This is the thickness of material required for the wave to be attenuated by $1 / \mathrm{e}$, or to about 37 percent of its initial value. Three skin depths corresponds to about 95 percent attenuation. The absorption can be expressed in terms of the skin depth as

$$
A=20(t / \delta) \log e
$$

The second component to EMI shielding is reflective attenuation. The exact form depends upon whether the noise is in the far field or the near field. If the noise is in the near field the form varies with whether the noise is voltage (electric field) or current (mignetic field) dominated.

Electro-magnetic radiation which is reflected from the far field is dependant only upon the frequency of the radiation, and the conductivity and permeability of the shield according to the relation,

$$
R_{\mathrm{f}}=245+10 \log _{10}(\sigma / \mu \mathrm{f})
$$

where " $R_{f}$ " is the far field reflective attenuation in $d B$.

If the noise is in the near field the dependence of shielding ability is a complex interaction of distance from the source, conductivity, permeability, and frequency. If the noise source radiation is dominated by the electric field the reflective attenuation has the form,

$$
R_{e}=400-10 \log _{10}\left(f^{3} r^{2} \mu \sigma^{-1}\right),
$$


where " $\mathrm{R}_{e}$ " is the electric component near field dominated reflection in $\mathrm{dB}$. If, however, it is dominated by the magnetic field the reflective attenuation follows the form,

$$
\mathrm{R}_{\mathrm{l}}=20 \log _{10}\left[\left(1.57 \times 10^{-6}\left(\mathrm{~m}^{3} \mathrm{~h} / \mathrm{s}\right)^{1 / 2}\left(\mu / \mathrm{r}^{2} \mathrm{f} \sigma\right)^{1 / 2}\right)+4.05 \times 10^{4}\left(\mathrm{~s} / \mathrm{m}^{3} \preccurlyeq\right)^{1 / 2}\left(\mathrm{r}^{2} \mathrm{f} \sigma / \mu\right)^{1 / 2}+0.354\right] \text {. }
$$

where " $\mathrm{R}_{\mathrm{h}}$ " is the magnetic component near field dominated reflection in $\mathrm{dB}$. Thus, when reflective losses are discussed, a specific geometry must be considered which is relevant to aerospace structures.

The third component of EMI shielding is that which arises from internal reflections within the shielding. These are waves which are reflected from the back surface of the shield, and then off of the front surface, and then finally emerge from the back surface, as is illustrated in figure 4. Unless a destructive interference pattern is set up with the primary transmitted beam, this will be a negative term, that is, it will lower the total shielding. If the absorption attenuation is greater than about $15 \mathrm{~dB}$, this effect will be minimal because the secondary reflected beam will be so weak. But in cases where $A$ is less than $15 \mathrm{~dB}$ (an electrically "thin" material) major effects can be observed at low frequency. Intuitively one would expect a complex interplay of wavelength and phase angle of the incident wave, shield thickness, and impedances of both the wave and the shield. This is indeed the case.

The internal reflection losses in $\mathrm{dB}(\mathrm{B})$ have the functional form,

$$
\mathrm{B}=20 \log _{10}|1-a \cos \phi+\mathrm{j} a \sin \phi|
$$

where

$$
\mathrm{j}=(-1)^{1 / 2}
$$

$$
\begin{gathered}
\phi=\mathfrak{t}(\sigma \mathrm{f} \mu)^{1 / 2} \\
a=\left[\left(\mathrm{Z}_{\mathrm{s}}-\mathrm{Z}_{\mathrm{w}}\right) /\left(\mathrm{Z}_{\mathrm{s}}+\mathrm{Z}_{\mathrm{w}}\right)\right]^{2} \times 10^{-0.1 \mathrm{~A}}
\end{gathered}
$$

" $\mathrm{A}$ " is the absorption, " $\mathrm{Z}_{\mathrm{s}}$ " is the intrinsic impedance of the shield defined as,

$$
Z_{s}=(1+j)(\mu f / 2 \sigma)^{1 / 2}\left(2.17 \times 10^{-12}\right)
$$

and " $\mathrm{Z}_{\mathrm{w}}$ " is the impedance of the incident wave, which for an electric component dominated wave has the form,

$$
\mathrm{Z}_{\mathrm{w}}=1 / c \epsilon_{\mathrm{o}}\left[\left(1+\mathrm{j} \beta \mathrm{r}-\beta^{2} \mathrm{r}^{2}\right) /\left(j \beta \mathrm{r}-\beta^{2} \mathrm{r}^{2}\right)\right]
$$

where "c" is the speed of light, and " $\beta$ " is $2 \pi$ /wavelength, and for a magnetic component dominated wave has the form,

$$
Z_{w}=\alpha \mu_{o}\left[\left(j \beta r-\beta^{2} r^{2}\right) /\left(1+j \beta r-\beta^{2} r^{2}\right)\right]
$$




\section{Spacecraft Shielding}

Whether near field or far field shielding is appropriate depends upon the wavelength of the noise and its distance from the source. Since spacecraft are usually isolated by large distances from external potential noise sources, only the noise sources on board the spacecraft need to be considered. Further, there are generalizations which can be made because all current spacecraft fall within a certain size range.

Spacecraft vary in size from atmospheric probes $(\approx 1$ meter length) to the space shuttle $(\approx 20$ meters length for the cargo bay area). Far field is considered being greater than $2 \pi$ times the wavelength from the source. For the shuttle this corresponds to a wavelength of about 3 meters, or a frequency of about $100 \mathrm{MHz}$. Thus, for frequencies less than about $100 \mathrm{MHz}$ (wavelengths longer than 3 meters), shielding in the near field is required, for frequencies greater than about $200 \mathrm{MHz}$, far field.

There are also lower limits to the spacing of noise sources. Electrical components may be packed within a box as close as $1 \mathrm{~cm}$. Using the line of reasoning from the larger scale, frequencies less than about $200 \mathrm{GHz}$ would require near-field shielding. This illustrated in figure 5 , and will be referred to in subsequent discussions.

\section{Shielding Requirements}

Exactly how much shielding is required to screen out EMI is a complex question. The working definition we stated before was any electro-magnetic radiation that has a disturbing influence on devices exposed to it. Different devices have different tolerances for electro-magnetic radiation. For example, a power converter may only require $20 \mathrm{~dB}$ shielding from its environment, whereas a communications receiver may require $60 \mathrm{~dB}$. If there is a particularly strong noise source decisions need to be made about how much to shield that single source as opposed to increasing the shielding to the rest of the components in the vicinity. Payloads to be carried on the Space Transportation System (Shuttle) must not only not interfere internally, but also must not interfere with Shuttle operations.

Sometimes one frequency response of the shielding is the over-riding concern. For example, Shuttle payloads must meet stringent requirements in the range of the Shuttle radar. If that is met then it is assumed the rest of the spectrum will not present a problem.

The interference mode is of utmost importance in minimizing EMI. If the principal interference mode is conduction along the power or ground buses, then active devices, such as isolation transformers, will be more important than the shielding enclosures. If the principal interference mode is radiative, then whether the EMI is in the near field or far field affects abatement measures. If the source is near field, it must be determined whether it is capacitively coupled (dominated by the electric field) or inductively coupled (dominated by the magnetic field).

Usually, the overall shielding ability of an enclosure is not dominated by diffusion of the radiation through the enclosure, but by leaks through penetrations and interfaces. 
Whether a gap will lead radiation depends upon the comparative size of the gap and the wavelength of the radiation. In general, if the gap is less than the wavelength, it will not allow radiation to escape. Thus, high frequency sources and receivers are more difficult to shield than low frequency.

In spacecraft the situation is further complicated by the fact that the EMI shield is multifunctional. It must also act as at least part of the radiation shield. The sun is a time varying source of high energy particles and radiation. During times of peak solar activity radiation fluxes as high as $10^{13} \mathrm{MeV} / \mathrm{cm}^{2}$-day are present, and many electrical components are sensitive to those levels of radiation. Heat must also be rejected through the shielding boxes. In vacuum only conductive and radiative heat rejection modes are available.

In practice, the limiting factor is often the mechanical characteristics that limit the EMI shield. Aluminum foil would have enough shielding ability for most applications, but does not have the structural integrity to build the spacecraft. The maximum stresses occur on second stage ignition, but these are usually small compared to ground-base handling loads. Thus, shield are usually engineered to take ground handling loads of 150 pounds, far more than is required during their operational life.

As with any spacecraft component, the major concern, however, is weight. The average cost to orbit per pound of hardware is shown in figure 6 . Saving a few pounds in a communications satellite may enable an additional transponder to be added, resulting in several millions dollars profit per year. A small weight saving may also allow enough additional station keeping fuel to extend the operational life of the satellite by years. If the weight savings is substantial, a smaller launch vehicle may even be able to be used which results in very substantial cost savings.

Thus, shielding requirements are a very complex issue. Improving the shielding ability beyond some nominal limit does not improve the overall electrical system performance, and present aluminum shields are clearly beyond that limit. What is needed is not an improvement in shielding ability, but an improvement in electrical system characteristics (such as specific power). Thus replacing an excellent shielding material which has high density or low strength with a moderate shielding material which has low density and high strength may result in higher specific power, because of lower system mass, and yet still have sufficient shielding characteristics.

\section{The Case for Graphite/Epoxy Composites}

The search for improved EMI shields must begin with a review of the properties of candidate materials. Such a list is presented in table I. Materials are listed in order of their density, thus, at a first look, materials located towards the bottom of the list are most desirable. Secondarily, the strength and modulus will be important since mechanical properties tend to be the limiting factor. Third, the resistivity is important to the shielding ability, and must be above some limiting value which will differ for different applications. 
The first candidate to consider would be the one at the bottom of the list, PANbased carbon fibers in an epoxy matrix. It has been found, unfortunately, that the resistivity of this material is too low to give adequate shielding for most applications. Beryllium has been used in cases where weight was extremely critical, but this material is not only expensive and difficult to work with, but also high toxic. This discussion will center in on the two materials located between beryllium and the PAN-based carbon fiber epoxy graphite, pitch-based graphite fiber/epoxy composite (such as P-100/epoxy), and intercalated pitch-based graphite fiber/epoxy composite (such as $\mathrm{P}-100+\mathrm{Br} /$ epoxy). Three grades of pitch-based graphite fiber will be considered; Amoco P-55, P-75, and P-100; along with their respective residual bromine intercalation compounds. The intrinsic impedances of these materials, as defined in equation (11), are shown over the frequency range of dc to $10^{12} \mathrm{~Hz}(1000 \mathrm{MHz})$ in figure 7.

To assess the possible impact of substituting intercalated graphite fiber composites for aluminum shielding boxes, some assumption will be made. Consider first a typical electronics package found aboard a communications satellite. A $5 \mathrm{~kg}$ electronics package is covered by a $2 \mathrm{~mm}(80$ mil) thick aluminum cover which measures $30 \mathrm{~cm} \mathrm{x} 30 \mathrm{~cm} \times 8$ $\mathrm{cm}$. Assume a simple substitution of the cover by an equal thickness of bromine intercalated P-100 epoxy composite of equal thickness and the weight of the cover is only 66 percent of the aluminum cover for a systems weight savings of 6.7 percent (see tab. II). But the composite cover is not only less dense, it is also stronger. An equal strength cover would only need to be $.35 \mathrm{~mm}$ ( 14 mil) thick and would weigh less than 12 percent of the mass of the aluminum cover. This would lead to a system weight savings of nearly 18 percent.

What effect would the saving of nearly 18 percent of the electrical system weight have on the total satellite? Table III shows the spacecraft weight breakdown of the interplanetary Pioneers, of the type that were flown to Venus, Jupiter and Saturn ${ }^{6}$. It is assumed that twenty percent of the weight of the communications system and the electrical system is made up of aluminum EMI shielding covers. If those cover were exchanged for GIC covers, $3.7 \mathrm{~kg}$ ( $8.2 \mathrm{lbs}$ ) of mass could have been saved. If this mass were to be added to the experiments payload, the payload mass could have been increased by more than 40 percent. Although there may be reasons (i.e. radiation shielding ability) why this full margin could not be realized, but it is obvious that a simple swap-out of covers, leaving the rest of the aluminum base structure in tact could lead to substantial payload mass increases.

Since the supporting structure represents about an additional 30 percent of the power system weight, if it also could be made from composite materials instead of aluminum the weight savings would be even more dramatic. A $6.0 \mathrm{~kg}$ conventional power package would weight a mere $3.6 \mathrm{~kg}$, a 40 percent savings.

\section{Calculated Shielding Ability of GIC Composites}

In order to calculate the shielding ability of GIC composites certain assumptions must be made. Perhaps the most important of these, as was mentioned above, is that the shielding ability is similar to that of isotropic metals of the same resistivity. Unfortunately, 
the resistivity of composite materials is subtle, and its value is dependent upon the measuring technique and the direction of its measurement. This is discussed in detail elsewhere. ${ }^{4}$ For the purpose of calculating the shielding effectiveness a simple rule of mixtures model was assumed.

Calculations were carried out using the equations described above for copper, aluminum, and 50 percent fiber volume fraction composites of PAN, P-55, P-75, P-100, P$55+\mathrm{Br}, \mathrm{P}-75+\mathrm{Br}$, and $\mathrm{P}-100+\mathrm{Br}$. It is assumed that the resin makes no contribution to the conductivity of the composites. Table IV lists the values of the properties needed in the analysis.

The absorptive attenuations per mm of material are shown in log-log scale in figure 8. From equation (4) it can be seen that the distance between the source and the shield is not a factor in determining the attenuation. Those materials which are most conducting are the most absorbing, and the attenuation rises steeply with frequency. In the range of tens of $\mathrm{GHz}\left(10^{10} \mathrm{~Hz}\right)$ and higher even the PAN fiber composites have excellent absorption (i.e. the skin depth is very short).

Far field reflective attenuation of the different materials are shown in a semi-log graph in figure 9. The assumption is that the source is far from the shield with respect to the wavelength of the radiation. Equation (5) reveals that far field reflection is independent of the shield thickness. Materials with the highest conductivity have the highest far field reflection, and it decreases with frequency. At the $\mathrm{kHz}\left(10^{3} \mathrm{~Hz}\right)$ frequency and below all of the materials are reflective enough to provide sufficient shielding. Note that the attenuation values for all of these materials are quite similar under these conditions.

The form of the near field reflective attenuation is dependant on whether the electric field or the magnetic field component of the wave is dominant. Relatively high voltage and low current waves are dominated by the electric field component and couple capacitively. Figure 10 shows the reflective attenuation of electric-field dominated electro-magnetic waves. Equation (6) shows that the source to shield distance is important for near field attenuation of this type of wave. The source to shield distance in this calculation was taken to be $10 \mathrm{~cm}$, and as the distance increases the reflective component of these wave will also increase. The frequency of a $10 \mathrm{~cm}$ wave is $3 \mathrm{GHz}\left(3 \times 10^{9} \mathrm{~Hz}\right)$, so the graph is not valid for frequencies higher than about that. Once again, the reflective attenuation does not vary a lot, but is somewhat is higher for more conductive materials and decreases with frequency.

If the noise is from a relatively high-current and low-voltage source, the magnetic component of the electromagnetic wave dominates and couples inductively. This leads to a different reflective attenuation as described by equation (7). Figure 11 is a semi-log plot which shows that over most frequencies the second term in equation (7) dominates. Once again the magnetic field attenuation is similar for all cases and the more conducting the material the better the reflective shielding. In this case, however, the attenuation increases with frequency. However, at low frequencies (below about $1 \mathrm{kHz}$ ), the first term of equation (7) dominates and lower conductivity materials have higher attenuation and the attenuation decreases with frequency. 
The attenuation which is due to internal reflection involves a complex interaction between the impedance of the incoming wave, the impedance of the shield, and the absorption and thickness of the shield. If the absorption exceeds about $15 \mathrm{~dB}$ then the magnitude of this term will be negligible. For this calculation the thickness of the shield was taken to be $1 \mathrm{~mm}$ and the source to shield distance $10 \mathrm{~cm}$. The internal reflection effects can be significant, especially in the low frequency regime.

Figure 12 reveals illustrates the internal reflection affects in the far field case. With lower conductivity materials the internal reflection term becomes more important, because the absorption is lower, both in magnitude and in frequency range affected. At very low frequency there is an amplification by as much as $50 \mathrm{~dB}$ for the less conducting composites. In the $\mathrm{MHz}\left(10^{6} \mathrm{~Hz}\right)$ range and above there is essentially no contribution from the internal reflections because the skin depth becomes significantly less than the shield thickness.

Figure 13 shows the near field internal reflection attenuation for the high impedance field case. The positions and widths of the resonance peaks are a strong function of the geometry, but are illustrative. In the case of the highly conductive metals and intercalated graphite composites there is little or no overshoot into the positive attenuation range. However, with the low conductivity cases, most notably PAN fiber composite, there is the look of a damped harmonic oscillator which does not totally damp out until frequencies around $10^{8} \mathrm{~Hz}$ are achieved. Once again there is no contribution once the near field region is passed (about $3 \times 10^{9} \mathrm{~Hz}$ ) when the near field condition fails to hold.

Figure 14 shows the near field internal reflection attenuation for the low impedance field case. The position and widths of the resonance peaks are greatly exaggerated even over that of the near field high-voltage low-current case. Even the copper and aluminum cases have an excursion near $-10 \mathrm{~dB}$ in the $10^{2} \mathrm{~Hz}$ range. This is because in inductively coupled fields the permeability $(\mu)$ of the shield becomes an important factor (see eqn. 13) and for copper and aluminum $\mu$ is nearly equal to 1 . Again the damped harmonic oscillator type behavior is damped out before the far field condition is met near $3 \times 10^{9} \mathrm{~Hz}$.

The total far field shielding is shown in figure 15. This is simply the sum of the curves in figures 8,9 , and 12 . The low frequency there is little absorption, and the frequency dependence of the reflection and the internal reflection terms cancel. The result is that the attenuation tends to be nearly frequency independent up to some characteristic value, after which it rises steeply due to the absorptive component.

For spacecraft far field shielding is important for frequencies above about $100 \mathrm{MHz}$ $\left(10^{8} \mathrm{~Hz}\right)$. The absorption of the metals, and the $\mathrm{P}-100+\mathrm{Br}$ and the $\mathrm{P}-75+\mathrm{Br}$ cause the shielding to rise sharply before this value. P-100 and $\mathrm{P}-55+\mathrm{Br}$ shielding begin their increases around $10^{8} \mathrm{~Hz}$, while P-75, P-55, and PAN composites have somewhat higher frequency thresholds. It is known that PAN composite shielding is not sufficient, and one would suspect that P-55 and P-75 would also have problems. The resistivity required for adequate shielding, however, depends upon the exact application.

The near-field high-voltage low-current shielding is the sum of the curves in figures 9,10 , and 13 , and is shown in figure 16. At low frequencies the absorption is insignificant, 
the reflective attenuation decreases as the cube of the frequency, and the internal reflection term increases as the square of the frequency. The result is that the total shielding in this region decreases proportionately to the log of the frequency. At $1 \mathrm{~Hz}$ the shielding is about $300 \mathrm{~dB}$, so at low frequency the shielding is very effective. At high frequency the absorptive attenuation is high, so the only concern is in the intermediate frequency region.

It is this region which is highlighted in figure 16 , and shows the value of intercalation. Intercalation shifts the trough to lower frequency and raises the lowest value. P-100 has its low value of about $48 \mathrm{~dB}$ at about $2 \times 10^{10} \mathrm{~Hz}$. Intercalation raises the minimum shielding to $77 \mathrm{~dB}$ and shifts the peak to $3 \times 10^{9} \mathrm{~Hz}$. Similar changes were noted with P-75 and P55. Intercalation becomes an enabling technology for graphite fiber/epoxy composites within the $\mathrm{GHz}$ and up frequency region.

The geometry of spacecraft is such that near-field shielding is required for frequencies less than about $200 \mathrm{GHz}\left(10^{11} \mathrm{~Hz}\right)$. Intercalated graphite composites thus open up a region of about $1-200 \mathrm{GHz}$ which heretofore could not be shielded with composites.

The near field high-current low-voltage shielding is the sum of curves shown in figures 8,11 , and 14. This is shown in figure 17. For power components the frequency range of interest is low, usually less that $100 \mathrm{kHz}\left(10^{5} \mathrm{~Hz}\right)$, so this is the frequency region of interest for this type of shielding. In this range absorption is minimal. The reflected attenuation is also low, less than $30 \mathrm{~dB}$ for any of the materials considered. To compound the problem internal reflection losses vary wildly over this range, depending on the exact geometry of the source and shield. The result is that the total shielding is minimal for highcurrent low-voltage sources in the near field.

The shielding problem is compounded because the wavelengths are so long at these frequencies that any reasonable spacecraft will be entirely within the near field. The only way to increase this sort of shielding is to use materials with large $\mu$ 's, that is ferromagnetic materials. In figure 18 the shielding provided by $1 \mathrm{~mm}$ of iron is shown. The permeability of iron is high enough that even $100 \mu \mathrm{m}$ of iron can provide adequate shielding if the frequency is in the $20 \mathrm{kHz}$ or larger range (see fig. 19). If graphite fibers can be intercalated to stage 2 with iron (III) chloride $\left(\mathrm{FeCl}_{3}\right)$, and this can be reduced to iron metal, this would provide the equivalent of more than $100 \mu \mathrm{m}$ of iron. The reduction of iron, nickel and cobalt graphite intercalation compounds has been achieved, ${ }^{7}$ but has yet to be reported with graphite fibers as the host.

\section{Preliminary Experimental Results}

Six formulations of composites were used for this study. Four-ply laminates (0.7 $1.0 \mathrm{~mm}$ thick) of 0-90 weave cloth made up of Amoco Thornel P-55, P-75, P-100, and their respective residual bromine intercalation compounds were fabricated. The properties of these laminates are summarized in table $\mathrm{V}$, and the details of their fabrication and characterization are described elsewhere. ${ }^{4}$ 
Samples of five of the composites (all except P-55+Br) were evaluated at Ferro Corporation Research Facilities, Independence, Ohio. Far field tests were conducted in the frequency range of $30-1000 \mathrm{MHz}$ using standard techniques which are described elsewhere. ${ }^{8}$ In all five cases the shielding attenuation exceeded $55 \mathrm{~dB}$, which was the limit of the equipment. In addition, the far field attenuation of a $\mathrm{P}-100+\mathrm{Br}$ composite samples was tested in the McDonnell-Douglas, St. Louis, MO mixed-mode chamber in the frequency range of $1-12 \mathrm{GHz}$. The shielding attenuation in this range exceeded $70 \mathrm{~dB}$, the limit of the equipment. All of these measurements are consistent with the calculations made above for far field measurements (see fig. 20).

Preliminary capacitively coupled near-field shielding tests were also carried out at Ferro Corporation in the $30-1000 \mathrm{MHz}$ range. These data indicated complex structure in their frequency dependence which casts doubt on their accuracy, but they do show that intercalation improves the shielding capability of the composites (fig. 21). The actual shielding values are somewhat lower than predicted by the theory, and given the anisotropic nature of the material, perhaps that is reasonable. But more data are required before firm conclusions can be made.

\section{Economic Trade-Offs}

The test of a new technology is whether it can accomplish a job better or cheaper than the present technology. It should by now be apparent that there is no shielding performance gain in switching from aluminum to intercalated graphite composites. The shielding ability of aluminum already far exceeds any requirement. If fact, it is the margin of excess that prompts inquiry. Better total power system performance and lower overall cost is what will drive replacement.

At first glance the cost benefits also appear to favor aluminum. The cost of a pound of 6061 aluminum is about \$4, whereas the cost of a pound of P-55, P-75, and P-100 fibers are $\$ 65, \$ 350$, and $\$ 900$ respectively. However, because of the superior mechanical characteristics of the graphite, when the required weights to replace a pound of aluminum are calculated the resulting costs are $\$ 4, \$ 20$, and $\$ 50$ for $\mathrm{P}-55, \mathrm{P}-75$, and $\mathrm{P}-100$ respectively. Furthermore, manufacturing costs favor the composites, especially if the volume is high or the shapes are complex. Bromine intercalation would add costs to the graphite, but it is a simple room temperature process which is not inherently expensive. ${ }^{9}$ Pristine and intercalated P-55, and perhaps even P-75 would be economically competitive with aluminum even if there were no benefits from weight reduction.

But the benefits from weight reduction may be considerable. In a communication satellite, for example, saving a few hundred grams would enable that much additional station keeping fuel to be carried on board, and the useful life might extended by months or years. Saving a few kilograms could enable the addition of an additional transponder and its associated support, which could mean several million dollars in additional profit annually. If several kilograms could be saved by perhaps replacing the frame and support structure as well as the shielding boxes, then perhaps a smaller launch vehicle could be used, and this would save millions of dollars in launch costs. Clearly the additional costs even 
from using intercalated P-100 fiber composites could be recovered may times over during the life of the mission.

It is interesting to note that the shielding performance of bromine intercalated P55 composite is calculated to be comparable to that of pristine P-100 composites. It may be more cost effective to utilize $\mathrm{P}-55+\mathrm{Br}$ than $\mathrm{P}-100$ composites, because of the cost differential between the fibers.

\section{CONCLUSIONS}

Calculations indicate that substantial weight savings (over 85 percent) can be realized by replacing conventional aluminum RFI shielding covers, providing that mechanical properties are the limiting factor. This could result in lowering the weight of the total power system by nearly 18 percent. Depending on the individual satellite, the percent payload increase may be very high, over 40 percent in the example of the interplanetary pioneers.

If the assumption can be made that composites shield in an analogous way to isotropic metals, then the shielding attenuation can be calculated. These calculations indicate that a range of shielding effectiveness can be fabricated by varying the fiber type. Intercalation can considerably enhance the shielding characteristics, and in fact may be enabling to the technology in frequency ranges of $1-1000 \mathrm{MHz}$.

Preliminary experiments support (although they certainly do not prove) the results of the calculations. Far field tests show attenuation of at least $55 \mathrm{~dB}$ in the $30-1000 \mathrm{MHz}$ range even for the case of pristine $\mathrm{P}-55$ composites. $\mathrm{P}-100+\mathrm{Br}$ show at least $70 \mathrm{~dB}$ shielding in the $1-12 \mathrm{GHz}$ range.

Adoption of this technology is likely to be cost critical. It is likely that the intercalation compounds of lower grade pitch fibers, such as P-55, may be considerably cheaper than pristine fiber of very high grade, such as P-100, with comparable performance. Thus, intercalated fiber composites could provide either higher performance or lower cost EMI shields than could be provided by their pristine counterparts.

\section{REFERENCES .}

1. See, for example, H. Oshima, J.A. Woollam, and A. Yavrouian, Journal of Applied Physics 53(12) (1982) 9220.

2. D.A. Jaworske, R.D. Vannucci, and R. Zinolabedini, Journal of Composite Materials 21 (1987) 580.

3. J.R. Gaier, M.E. Slabe, and N. Shaffer, Carbon 26 (1988) 381. 
4. J.R. Gaier, P.D. Hambourger, and M.E. Slabe, NASA Technical Memorandum 102567 (1990).

5. R.E. Taylor, Radio Frequency Interference Handbook, NASA SP-3067 (1971) 116.

6. W.R. Corliss, The Interplanetary Pioneers Volume II: System Design and Development, NASA SP-279 (1972) 16.

7. Ph. Touzain, A. Chamberod, and A. Briggs, Materials Science and Engineering 31 (1977) 77.

R. Yazami, Ph. Touzain, Solid State Ionics 9-10 (1983) 489.

R. Yazami, Ph. Touzain, G. Chouteau, and A. Briggs, Synthetic Metals 12 (1985) 485 .

8. M.A. Centanni and E. Clark, Extended Abstracts: Graphite Intercalation Compounds (Materials Research Society, 1986) 219.

9. J.R. Gaier, Synthetic Metals 22 (1987) 15. 
TABLE I. - PROPERTIES OF SHIELDING MATERIALS

\begin{tabular}{|l|c|c|c|c|}
\hline \multicolumn{1}{|c|}{ Material } & $\begin{array}{c}\text { Densi ty } \\
\mathrm{g} / \mathrm{cm}^{3}\end{array}$ & $\begin{array}{c}\text { Resistivity, } \\
\mu \Omega-\mathrm{cm}\end{array}$ & $\begin{array}{c}\text { Strength, } \\
\mathrm{MPa}\end{array}$ & $\begin{array}{c}\text { Modulus } \\
\mathrm{GPa}\end{array}$ \\
\hline Copper & 8.96 & 1.78 & 420 & 110 \\
Iron & 7.86 & 10 & 200 & 200 \\
Aluminum alloy & 2.80 & 10 & 520 & 71 \\
Aluminum & 2.70 & 2.82 & 210 & 60 \\
Beryllium & 1.85 & 4.0 & 620 & 290 \\
P-100+Br/epoxy & 1.78 & 90 & 840 & 430 \\
P-100/epoxy & 1.72 & 460 & 840 & 430 \\
T-300/epoxy & 1.51 & 5000 & 3200 & 228 \\
\hline
\end{tabular}

TABLE II. - MASS SAVINGS FROM EMI SHIELDED COMPOSITE SUPPORT STRUCTURE

\begin{tabular}{|l|r|r|r|}
\hline & Aluminum & $\mathrm{P}-100+\mathrm{Br}_{2} /$ epoxy & $\mathrm{P}-100+\mathrm{Br}_{2} /$ epoxy \\
\hline Thickness, mil $(\mathrm{cm})$ & $80(0.20)$ & $80(0.20)$ & $14(0.035)$ \\
Specimen strength, MPa-cm $/ \mathrm{g}$ & 78 & 470 & 83 \\
Density, g/cm & 2.70 & 1.78 & 1.78 \\
Shield mass, g & 1000 & 662 & 116 \\
Electronics in & & & \\
6 kg package, g & 5000 & 5338 & 5884 \\
Mass savings, percent & 0 & 6.7 & 17.7 \\
\hline
\end{tabular}

TABLE III. - SPACECRAFT WEIGHT BREAKDOWN OF INTERPLANETARY PIONEERS

\begin{tabular}{|l|r|c|c|}
\hline \multicolumn{1}{|c|}{ Subsystem } & $\begin{array}{c}\text { Weight, } \\
\text { lb }\end{array}$ & $\begin{array}{c}\text { Percent } \\
\text { total }\end{array}$ & $\begin{array}{c}\text { Wi th GIC } \\
\text { covers, } \\
\text { lb }\end{array}$ \\
\hline Structure & 17.4 & 13.8 & 22.4 \\
Communications & 27.6 & 22.0 & 12.8 \\
Electrical system & 15.8 & 12.6 & ---- \\
Reorientation system & 8.4 & 6.7 & ---- \\
Temperature control & 3.2 & 2.5 & --- \\
Bolar cell array & 17.7 & 14.1 & ---- \\
Delance weights & 1.5 & 1.2 & --- \\
Cont ingency & 9.5 & 7.5 & ---- \\
Experiments & 4.6 & 3.7 & ---- \\
\hline
\end{tabular}


TABLE IV, - PROPERTY VALUES USED

IN EMI SHIELDING CALCULATIONS

\begin{tabular}{|l|r|}
\hline \multicolumn{1}{|c|}{ Property } & $\begin{array}{c}\text { Value } \\
\mu \Omega-c m\end{array}$ \\
\hline Resistivity & \\
Copper & 1.8 \\
Aluminum & 2.8 \\
P-100+Br & 100 \\
P-75+Br & 200 \\
P-55+Br & 600 \\
P-100 & 500 \\
P-75 & 1000 \\
P-55 & 1800 \\
PAN & 4000 \\
\hline Thickness, mm & 1.0 \\
Source to shield, cm & 10.0 \\
\hline
\end{tabular}

TABLE V. - PHYSICAL PROPERTIES OF LAMINAR COMPOSITES

\begin{tabular}{|l|c|c|c|c|c|c|}
\hline & \multicolumn{2}{|c|}{ P-55 } & \multicolumn{2}{c|}{ P-75 } & \multicolumn{2}{c|}{ P-100 } \\
\cline { 2 - 7 } & pris & $\mathrm{Br}_{2}$ & pris & $\mathrm{Br}_{2}$ & pris & Br $_{2}$ \\
\hline Fiber volume percent & 56.2 & 54.0 & 58.7 & 58.5 & 64.0 & 48.0 \\
Resin weight percent & 28.0 & 31.0 & 27.6 & 30.6 & 24.3 & 38.7 \\
Void volume percent & 6.5 & 3.8 & 5.0 & 0.0 & 2.9 & 0.0 \\
Fiber density, g/cm & 2.182 & 2.214 & 2.059 & 2.141 & 2.039 & 2.293 \\
Resin density, g/cm & 1.265 & 1.265 & 1.265 & 1.265 & 1.265 & 12.65 \\
\hline
\end{tabular}


GRAPHITE

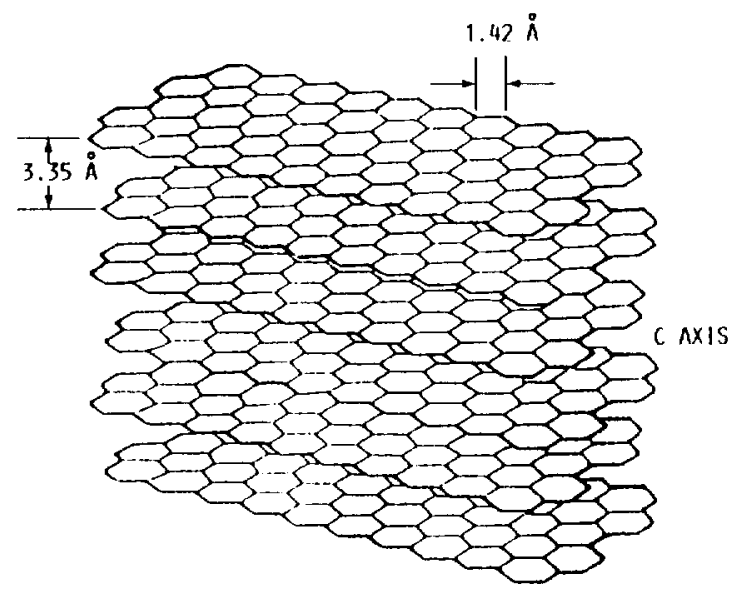

A AxIS

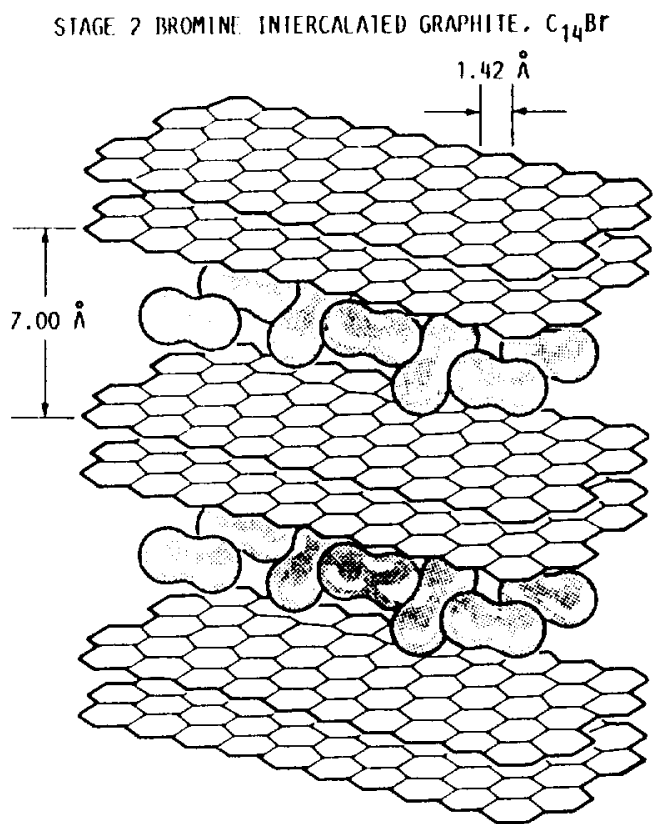

A AXIS

FIGURE 1. - INIERCALAIION OF GRAPHIIE.

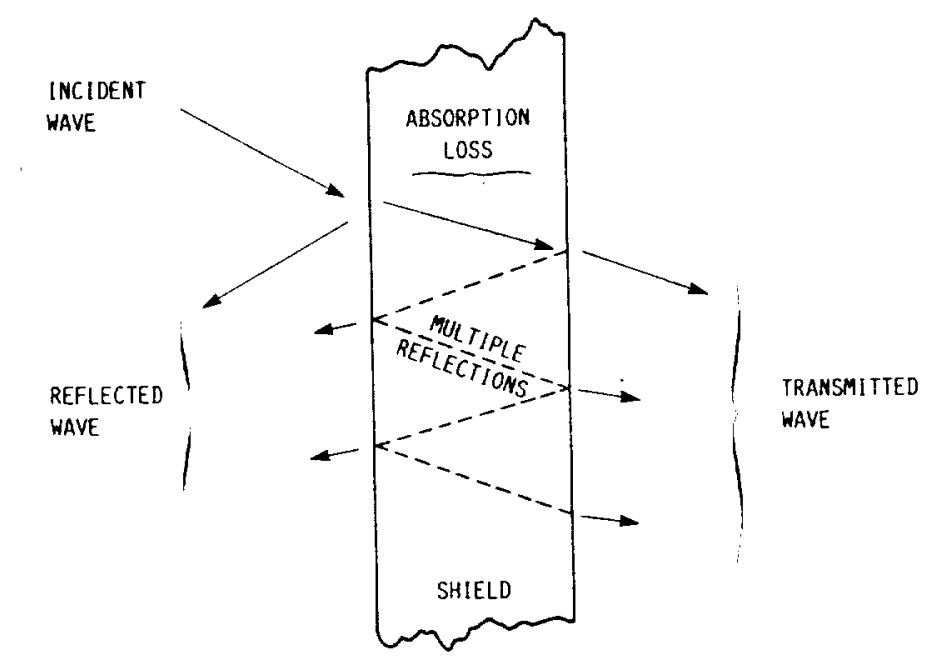

FIGURE 2. - SHIELDING EFFECTIVENESS. 


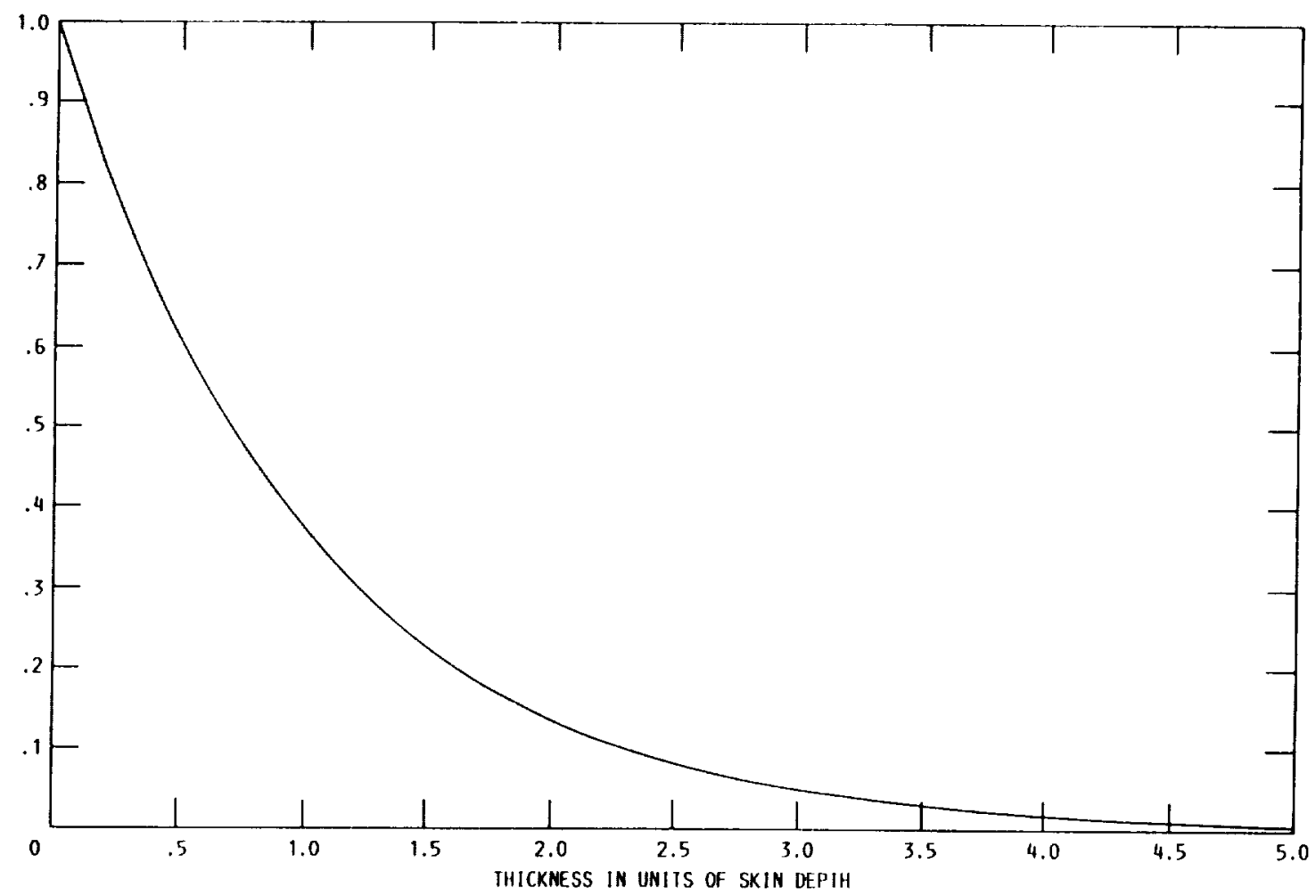

FIGURE 3. - MBSORPIION OF ELECIRO-MAGNETIC RADIATION.

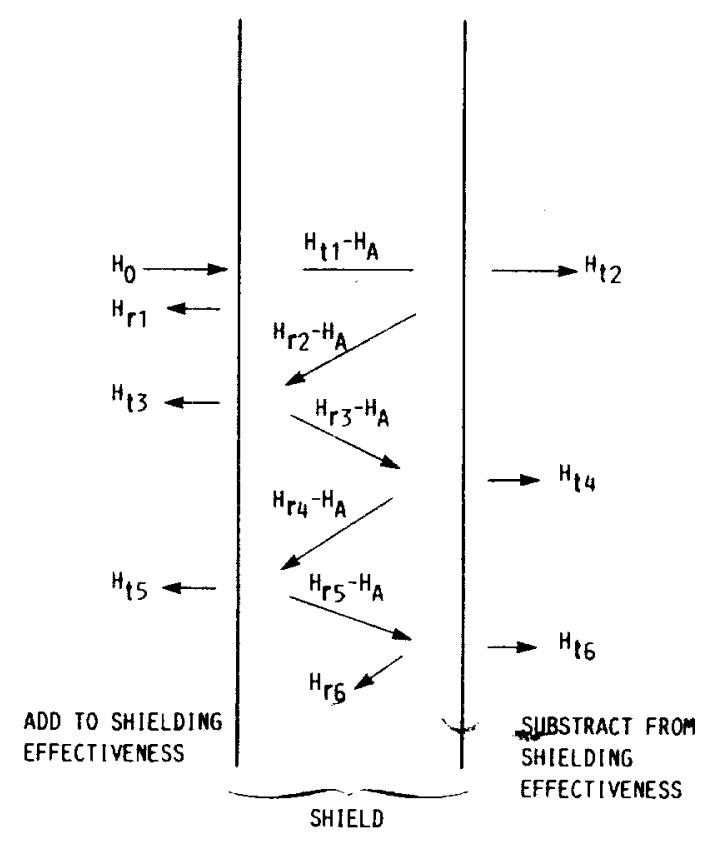

FIGURE 4. - MULTIPLE REFLECTIONS OF A MAGNETIC FIELD WITHIN A SHIELD WHERE HO IS THE INCIDENT FIELD. H IS THE ABSORPTION OF THE SHIELD. HIn IS THE TRANSMISSION THROUGH THE " $\mathrm{TH}$. REFLECTED WAVE AND $\mathrm{H}_{\mathrm{rn}}$ IS THE REFLECTION THROUGH THE " $n$ TH. REFLECTED HAVE. 


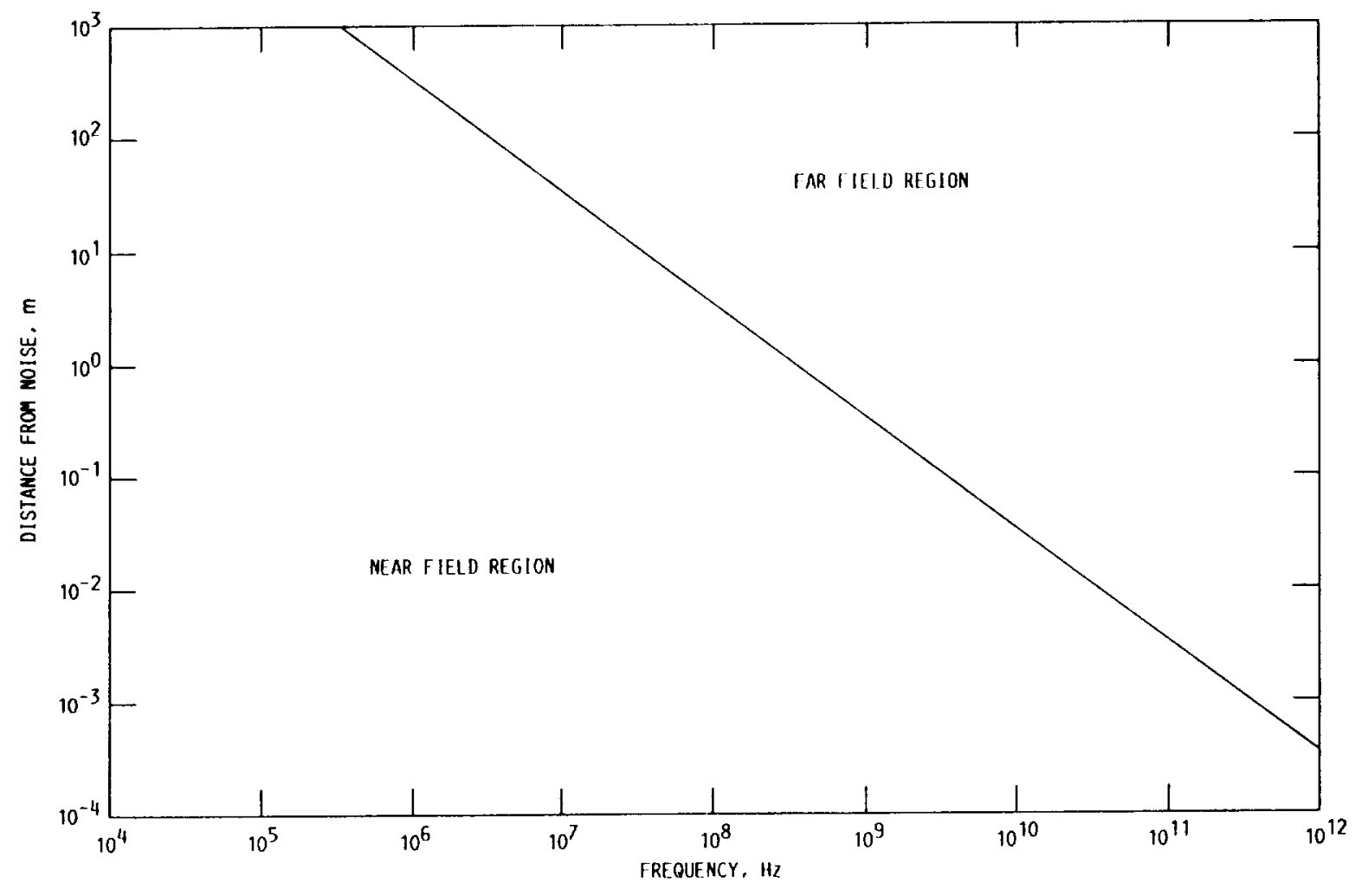

FIGURE 5, - ELECIROMUGETIC INIFRIERENCT MOIES.

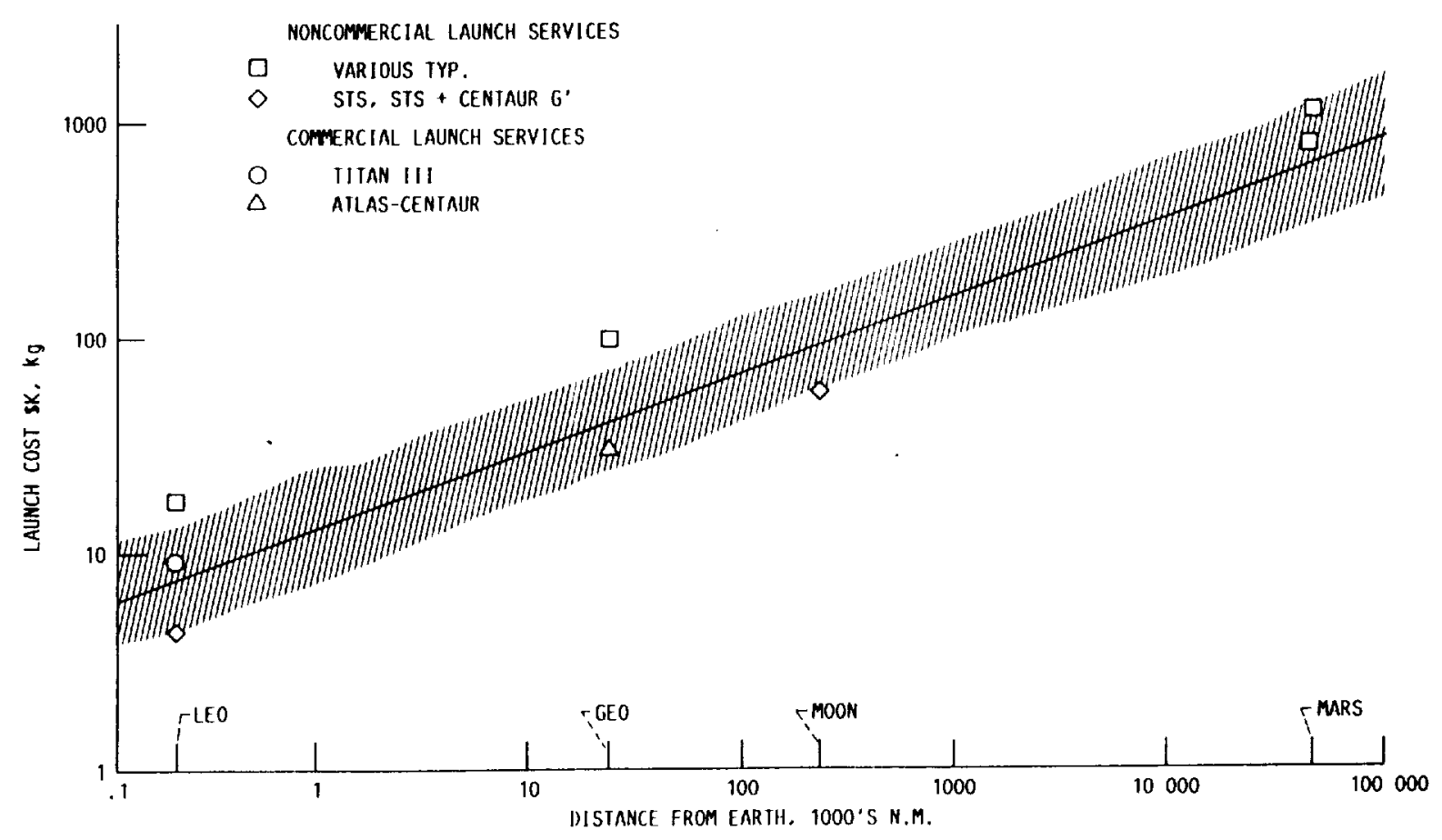

FIGURE 5. - 1988 COST OF DELIVERING $1 \mathrm{~kg}$ PAYLOAI) TO ORBIT. AOVANCED LAUNCH SYSTEM NOT INCLUDED. 


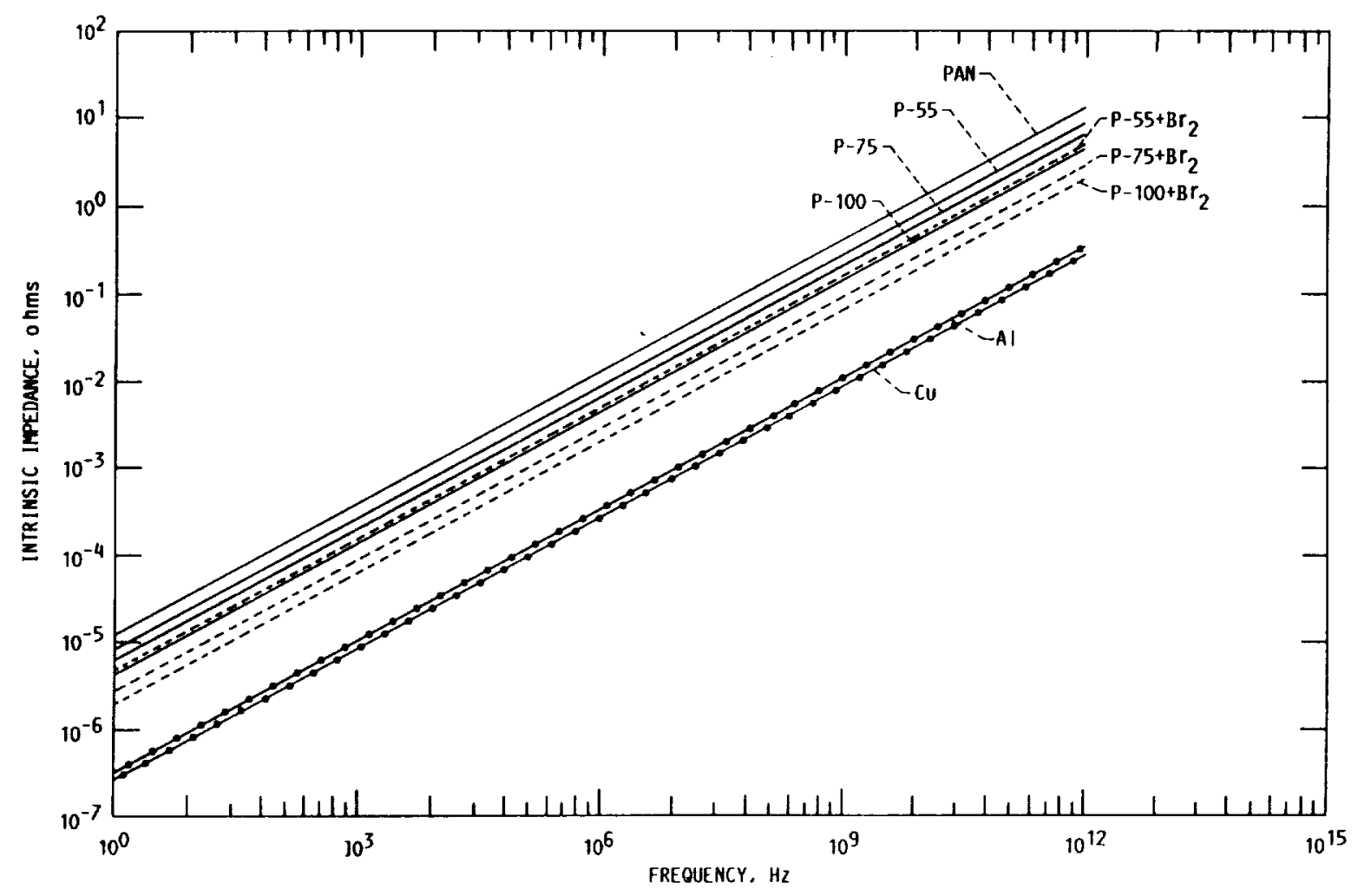

FIGURE 7. - INIRISIC IMPEDANCE OF SHIELDING MAIERIALS.

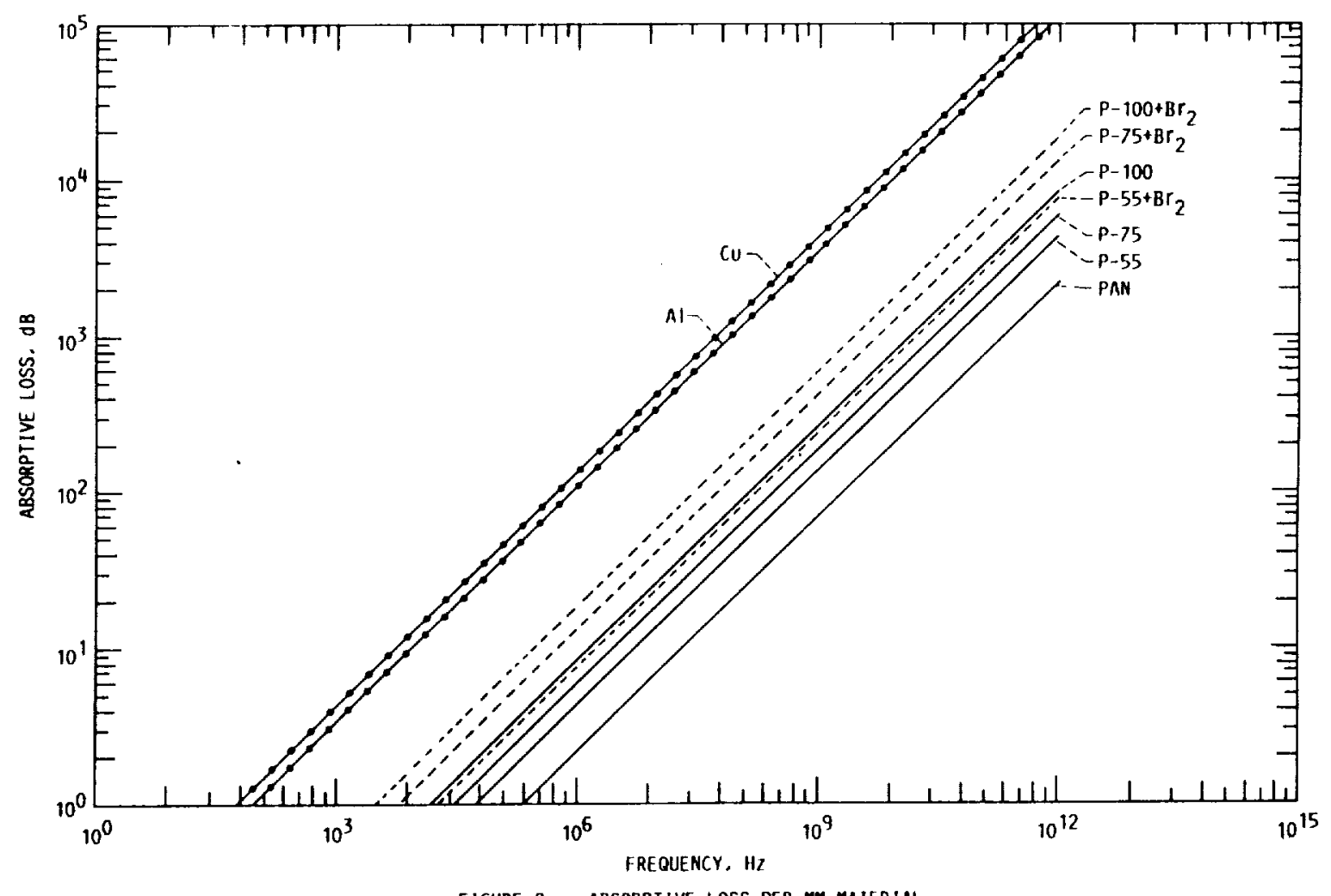

FIGURE 8, - ABSORPTIVE LOSS PER MMIERIAL. 


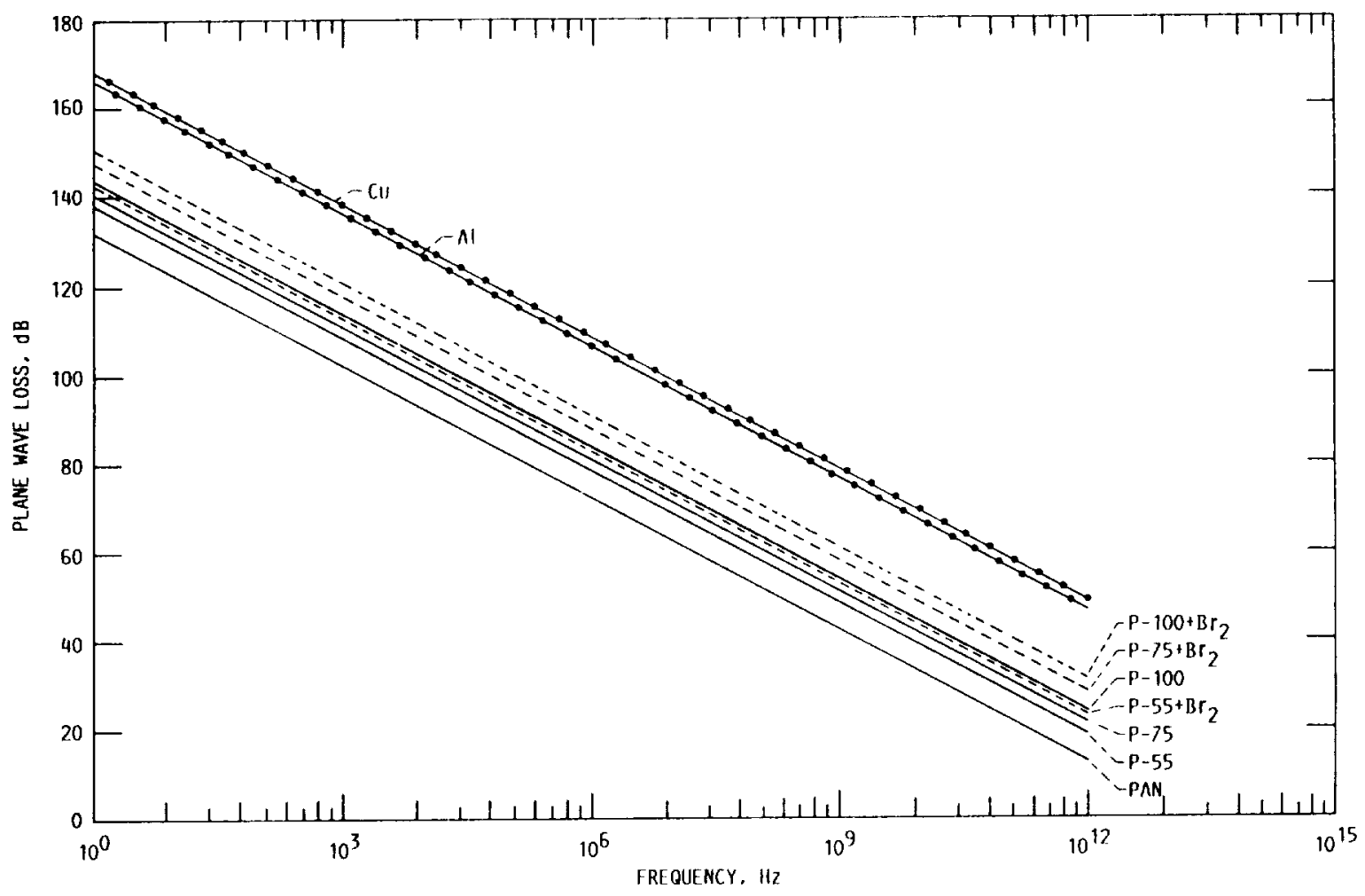

FIGURT. 9. - REFIECIIVE AITENUATION IN THE TAR IIILLD.

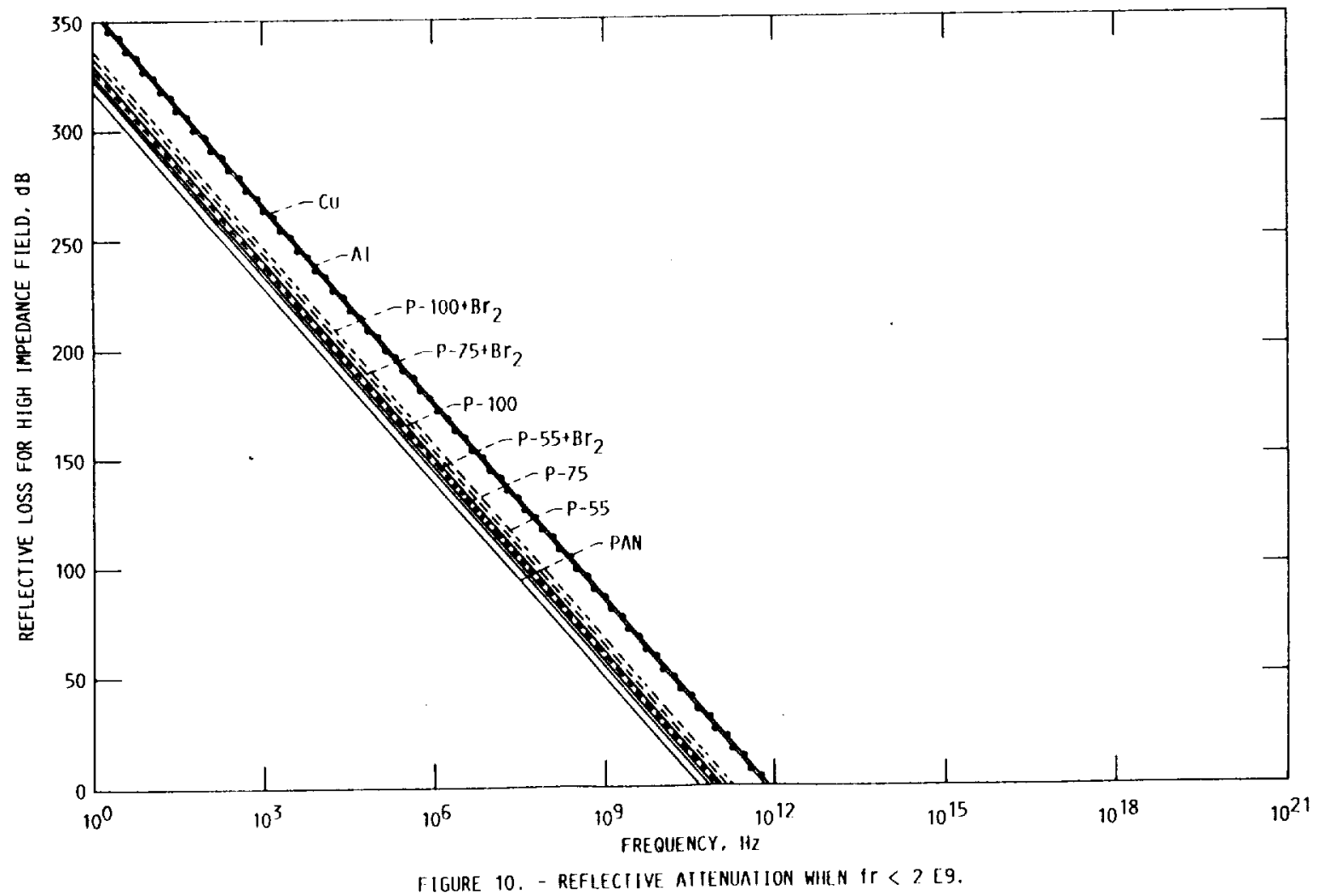



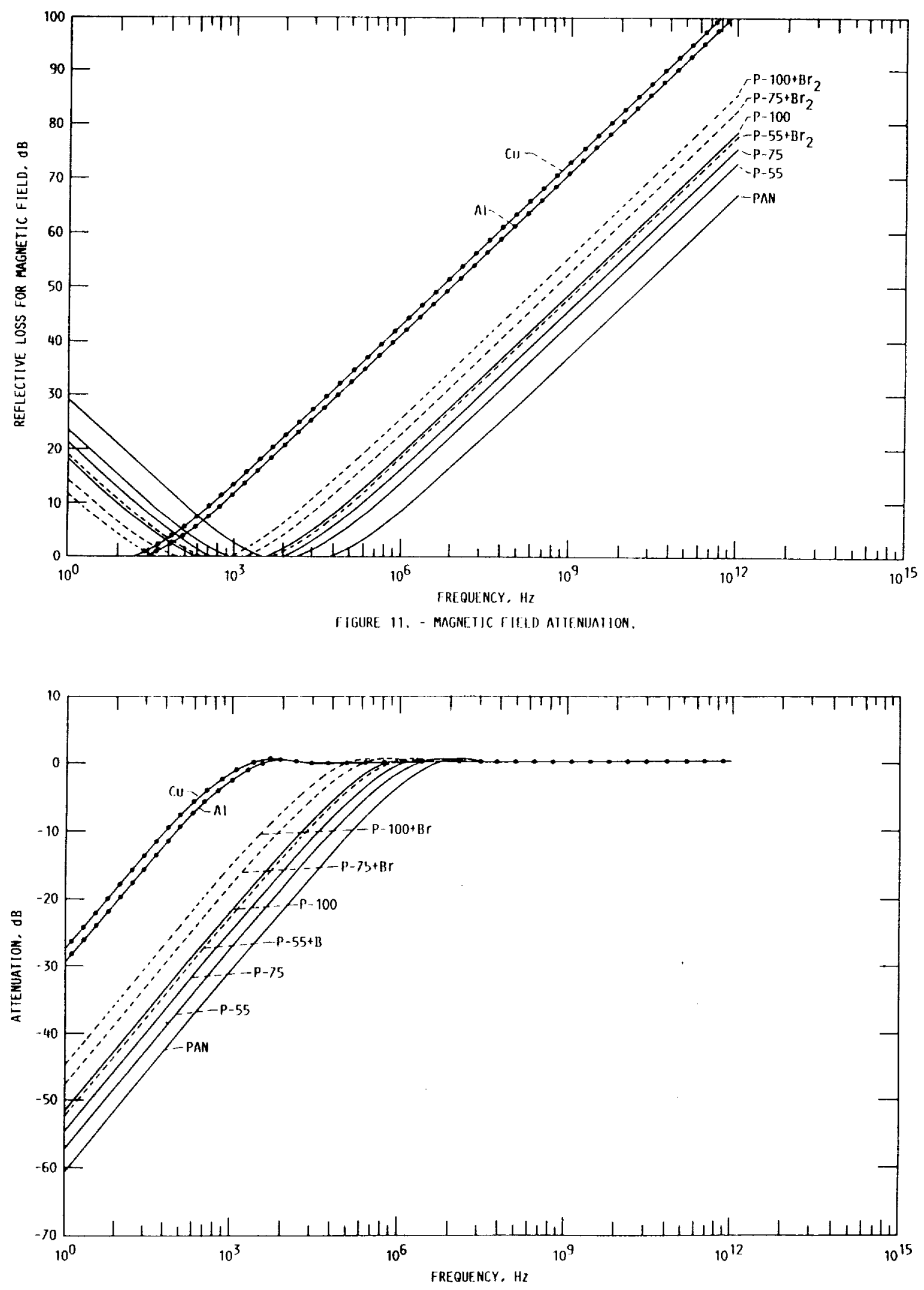

FIGURE 12. - INIERNAL REFLECIION AITENUAIION IN IIIE TAR FIELU). 


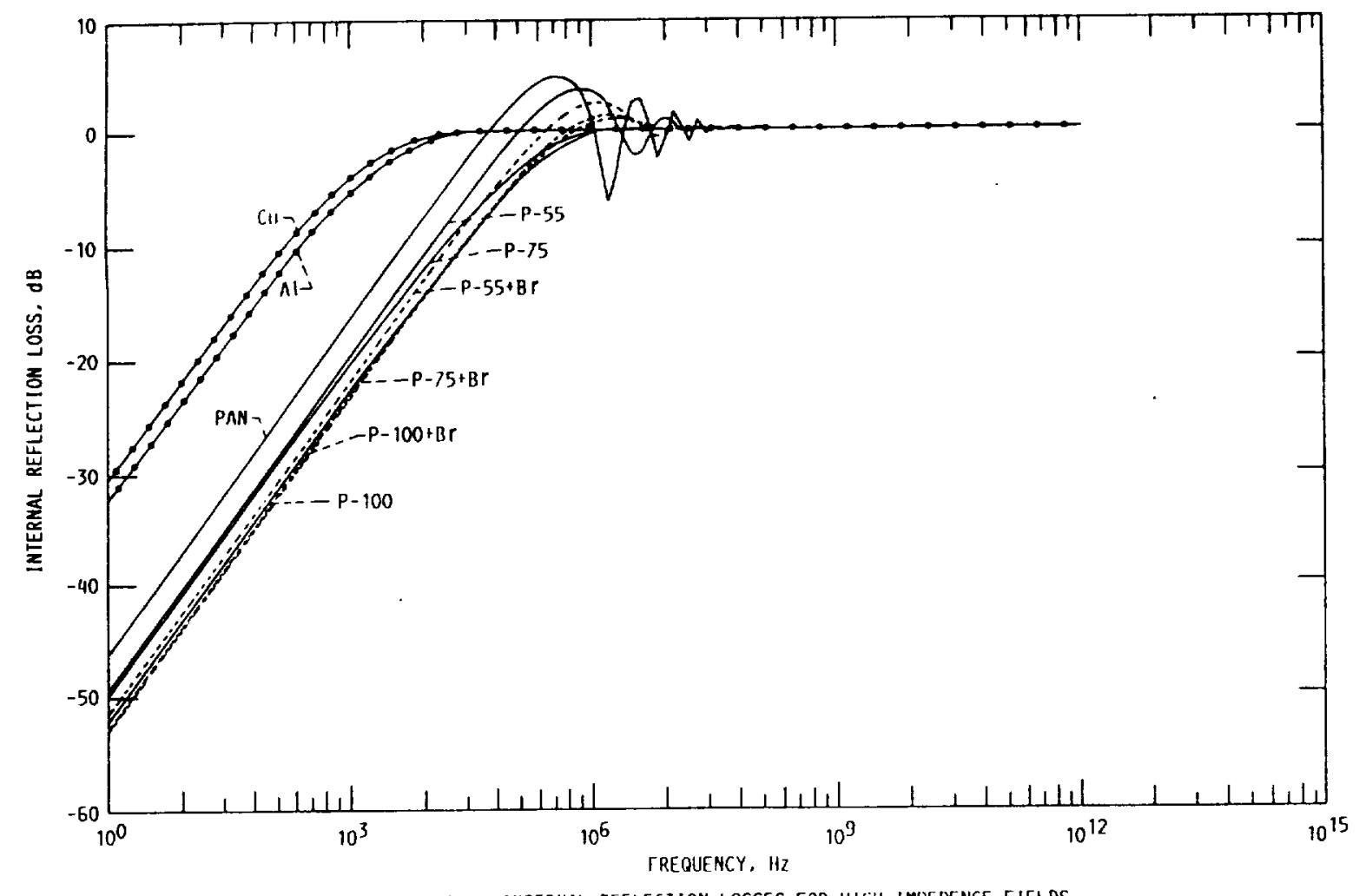

FIGURE 13. - INTERNAL RETLFCTION LOSSES FOR HIGH IMPEDENCE FIELDS.

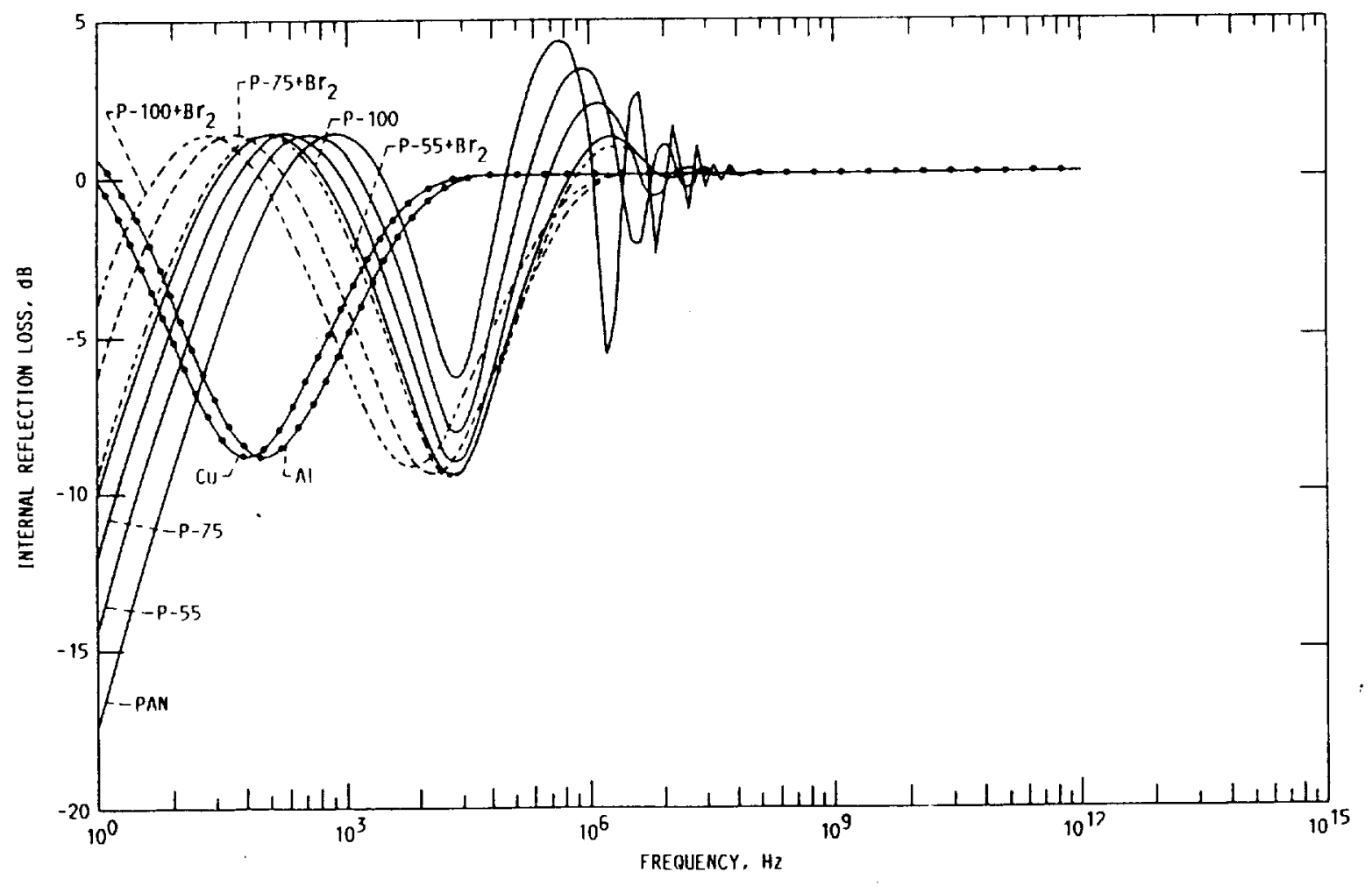

FIGURE 14. - INIERNAL REFLECTION LOSSES FOR LOW IMPEDENCE FIELDS. 


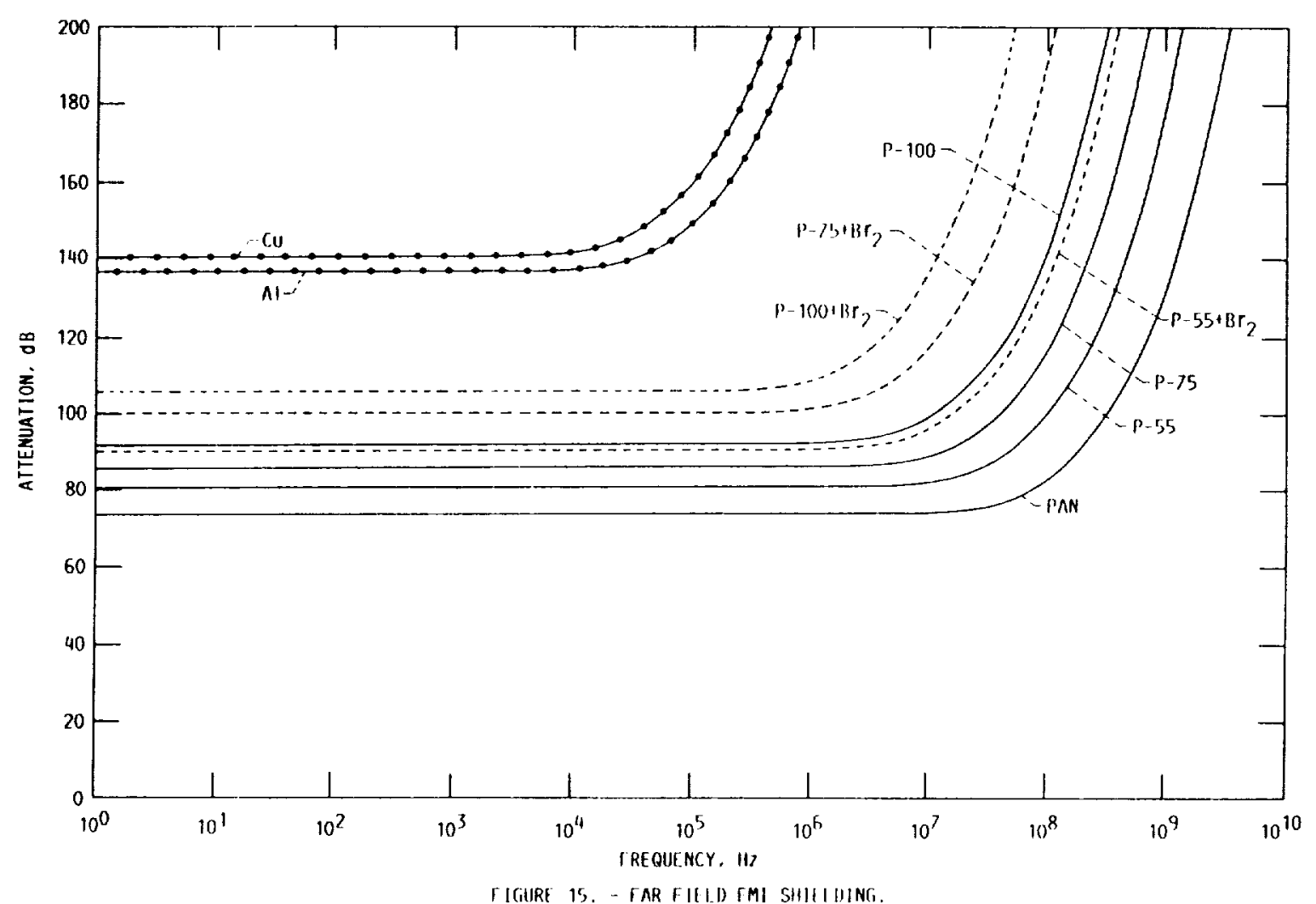

FIGIIRE 15. - TAR FILID FMI SHHIIIIING.

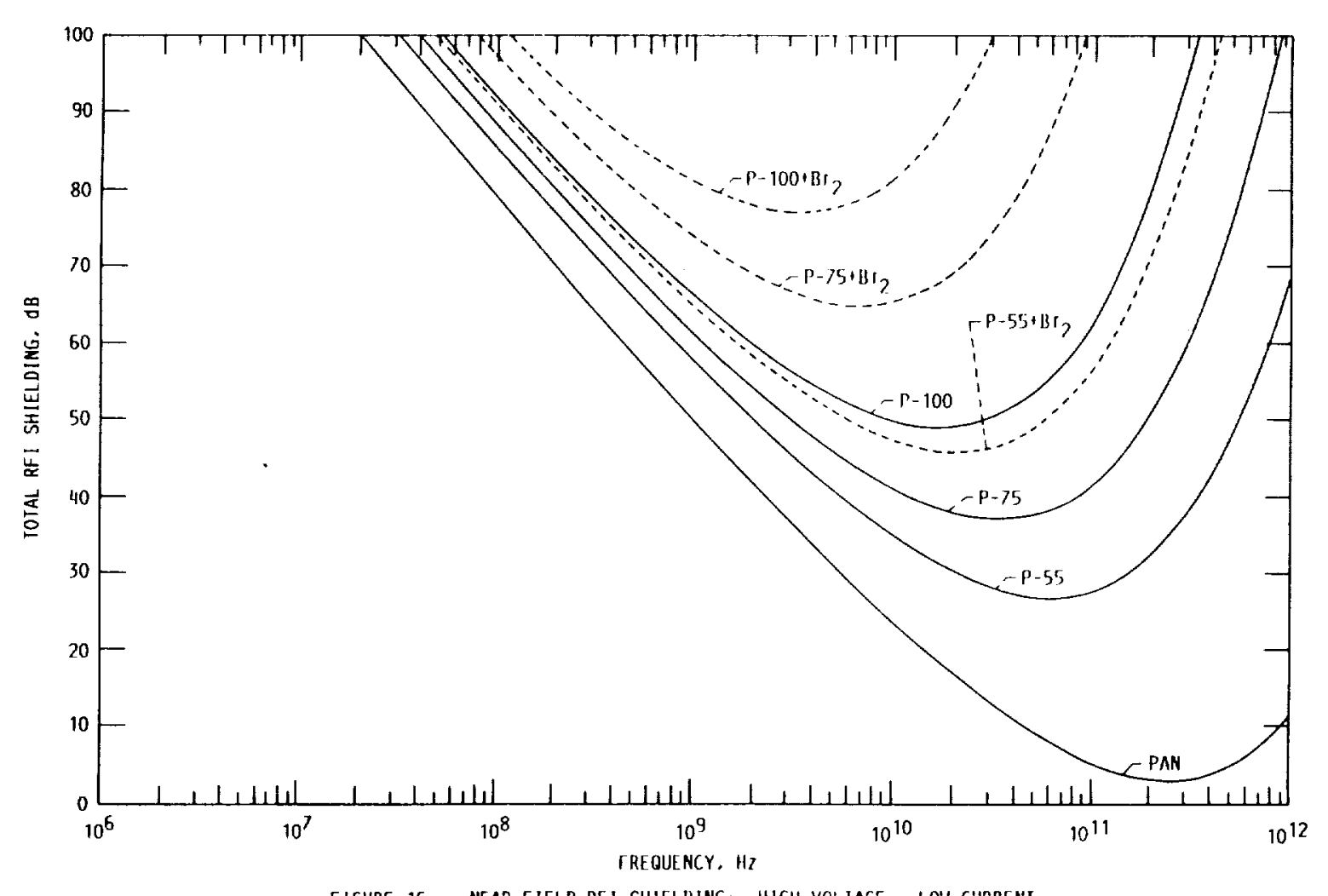

FIGURE 16. - NEAR FIELD RFI SHIELINING: HIGH VOLIAGE - I.OH CURRENI. 


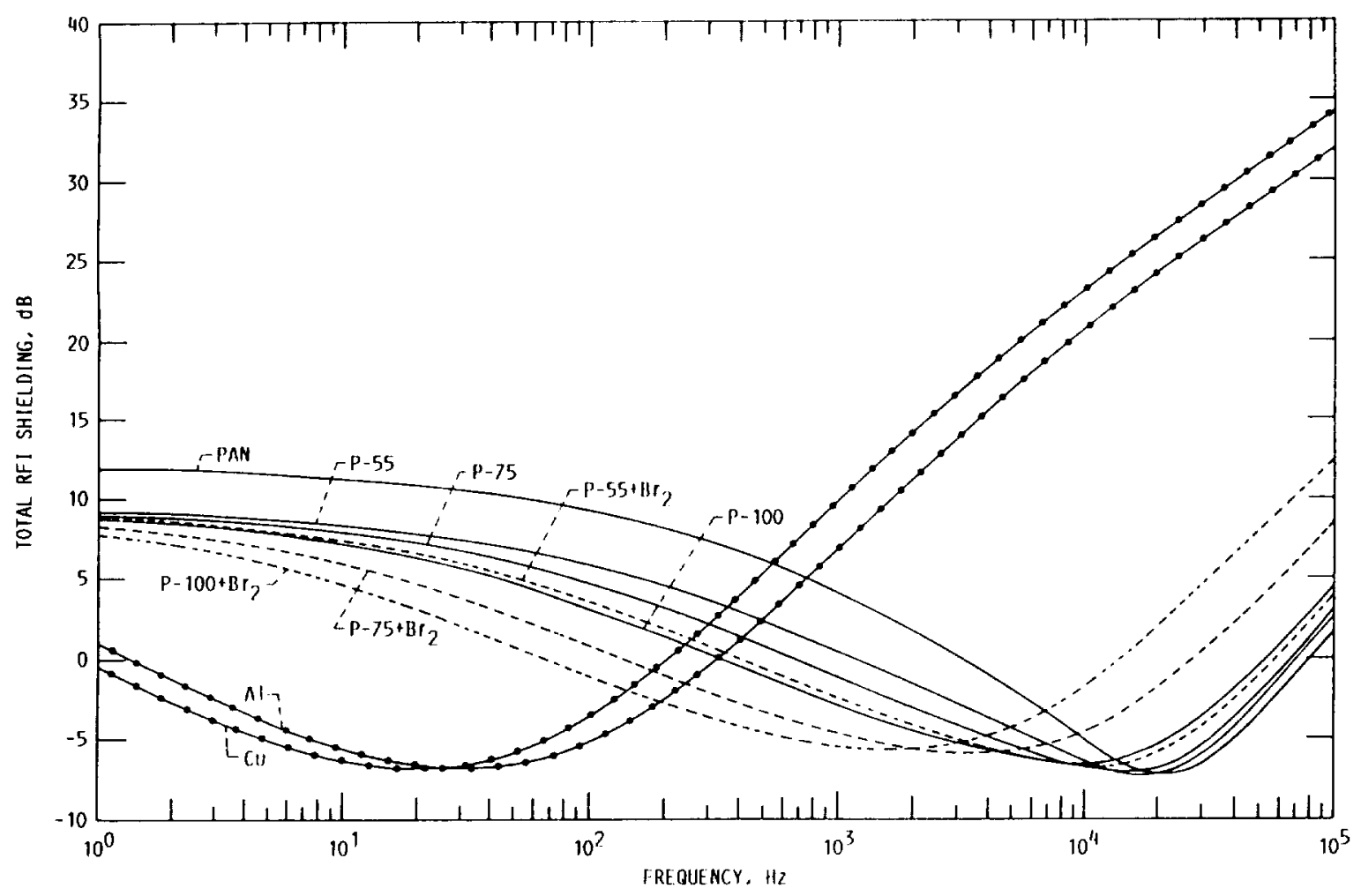

FIGIIAE 17. - NEAR FIELD RFI SIIIELDING: I.OW VOI IAGL - HIGII CURRFNI.

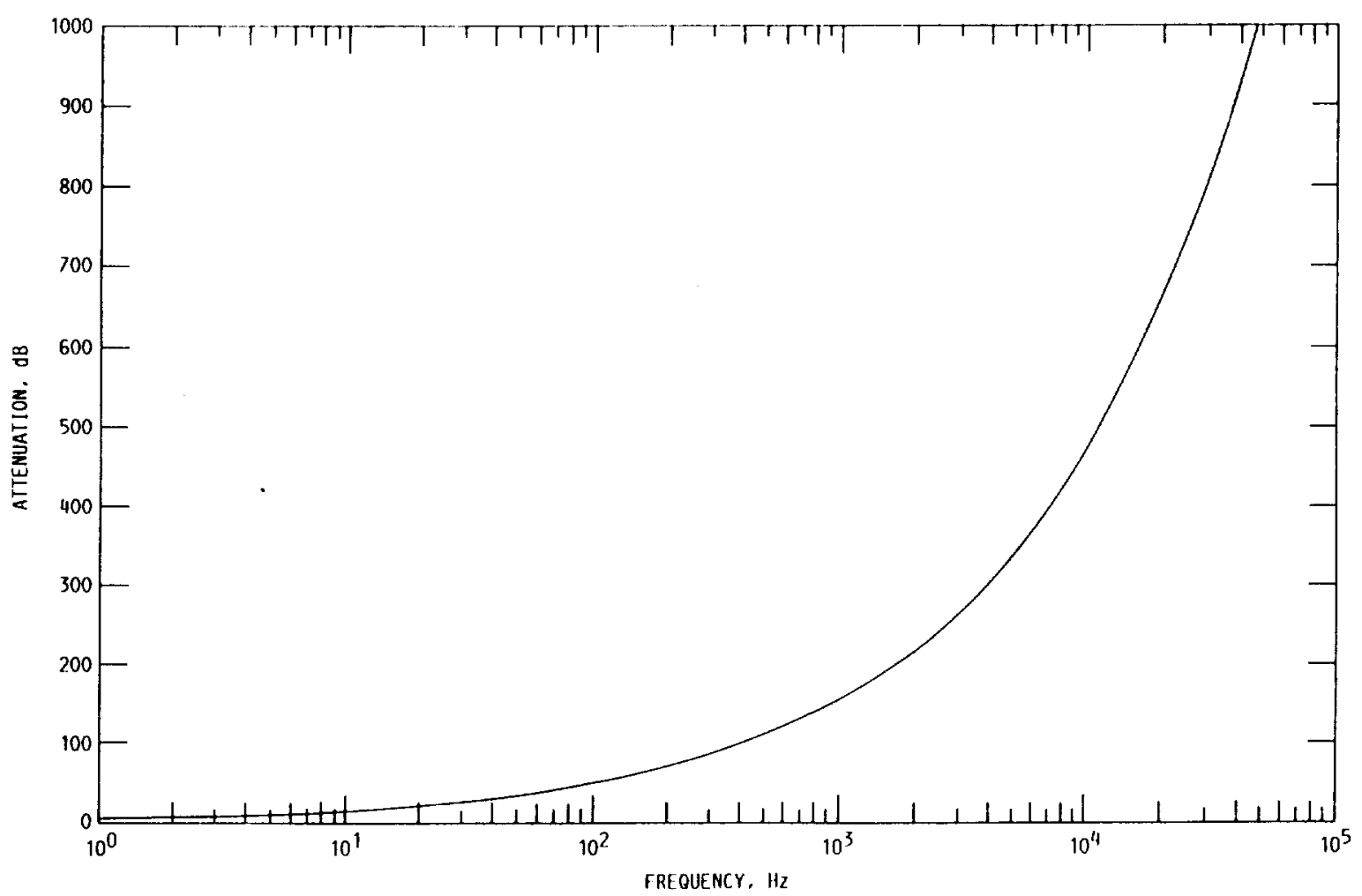

FIGURE 18, - NEAR FIELD SHIELDING OF $1 \mathrm{~mm}$ IRON: IOW VOI IAFE. - HIGH CURRENI. 


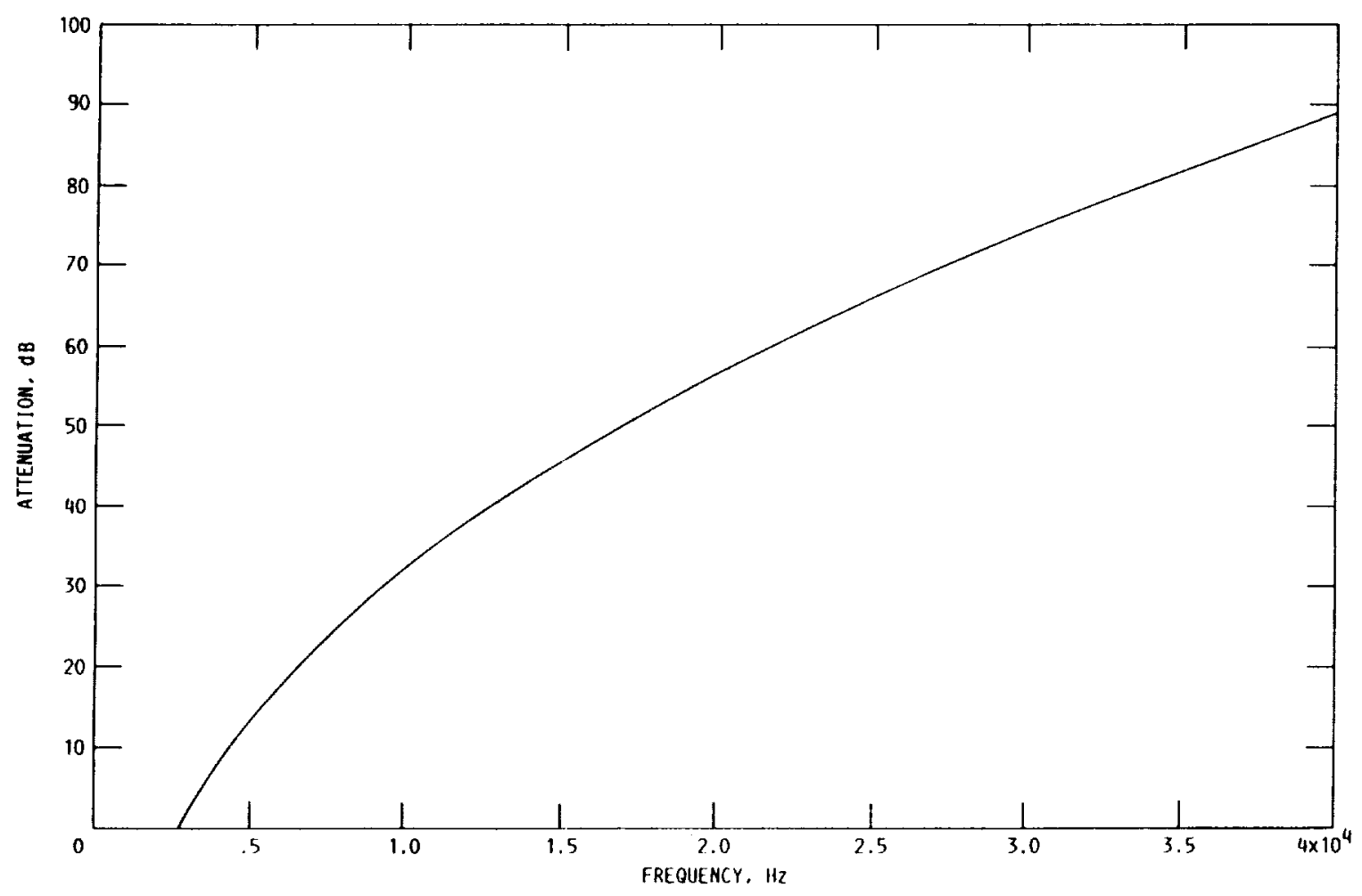

FIGURE 19. - MEAR FIELD SHEILDING OF $100 \mu \mathrm{m}$ IRON: LOW VOLIAGE - HIGH CURRENI. 


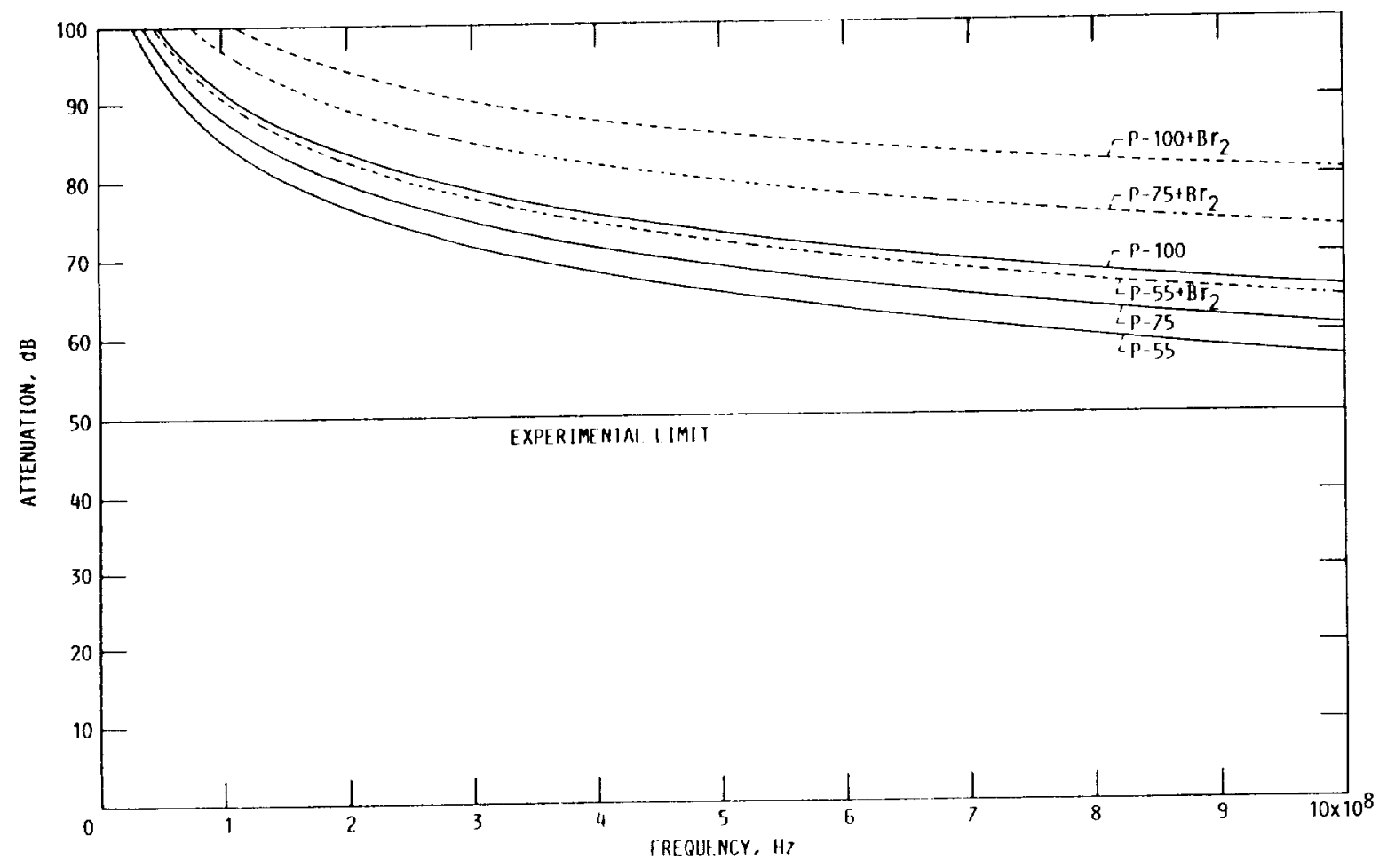

(a) NEAR FIEID.

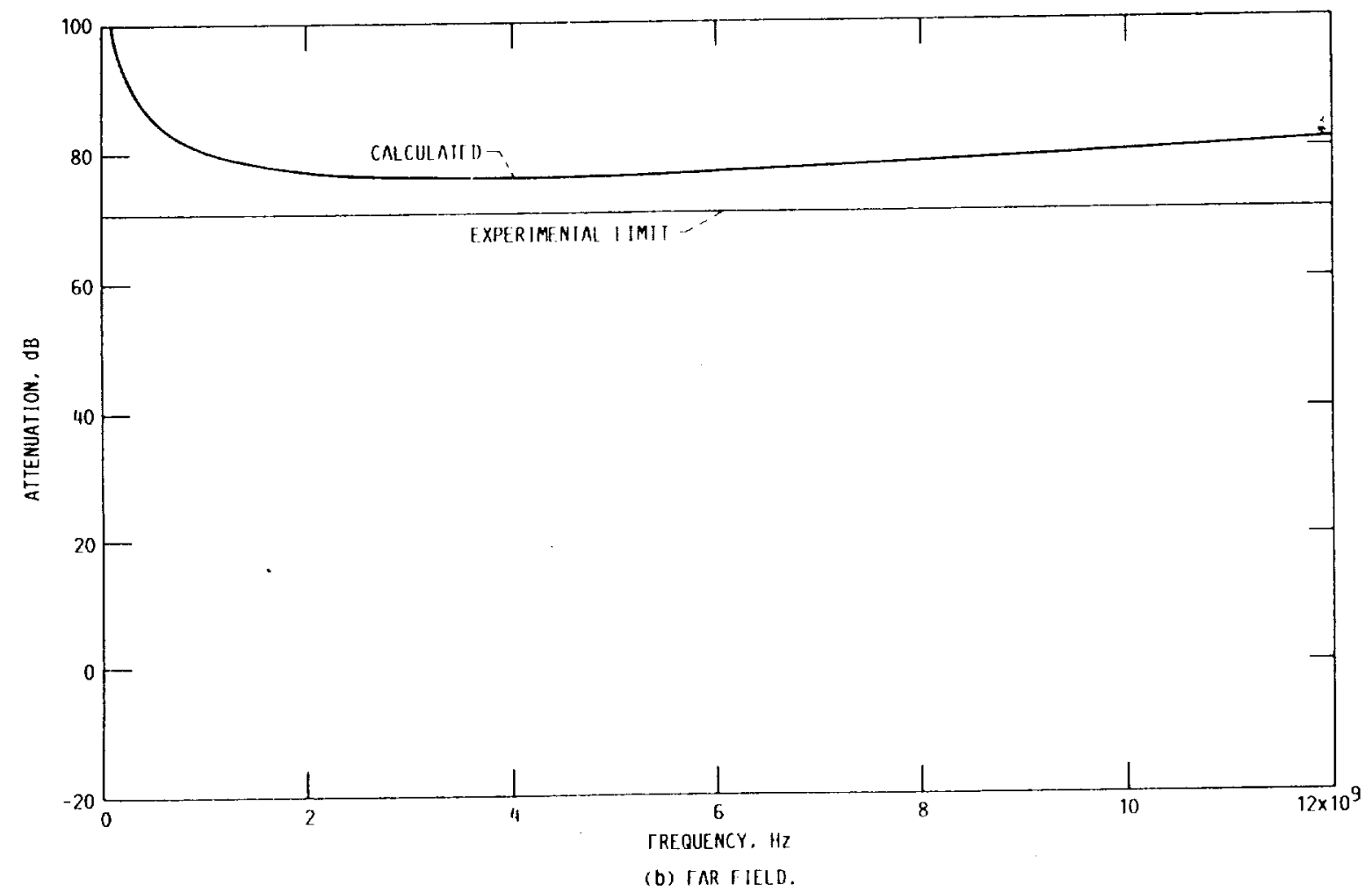

FIGIIRE 20. - HIGH IMPE DE NCF. SHIEIDING IOR P-100!Br COMPOSITE. 


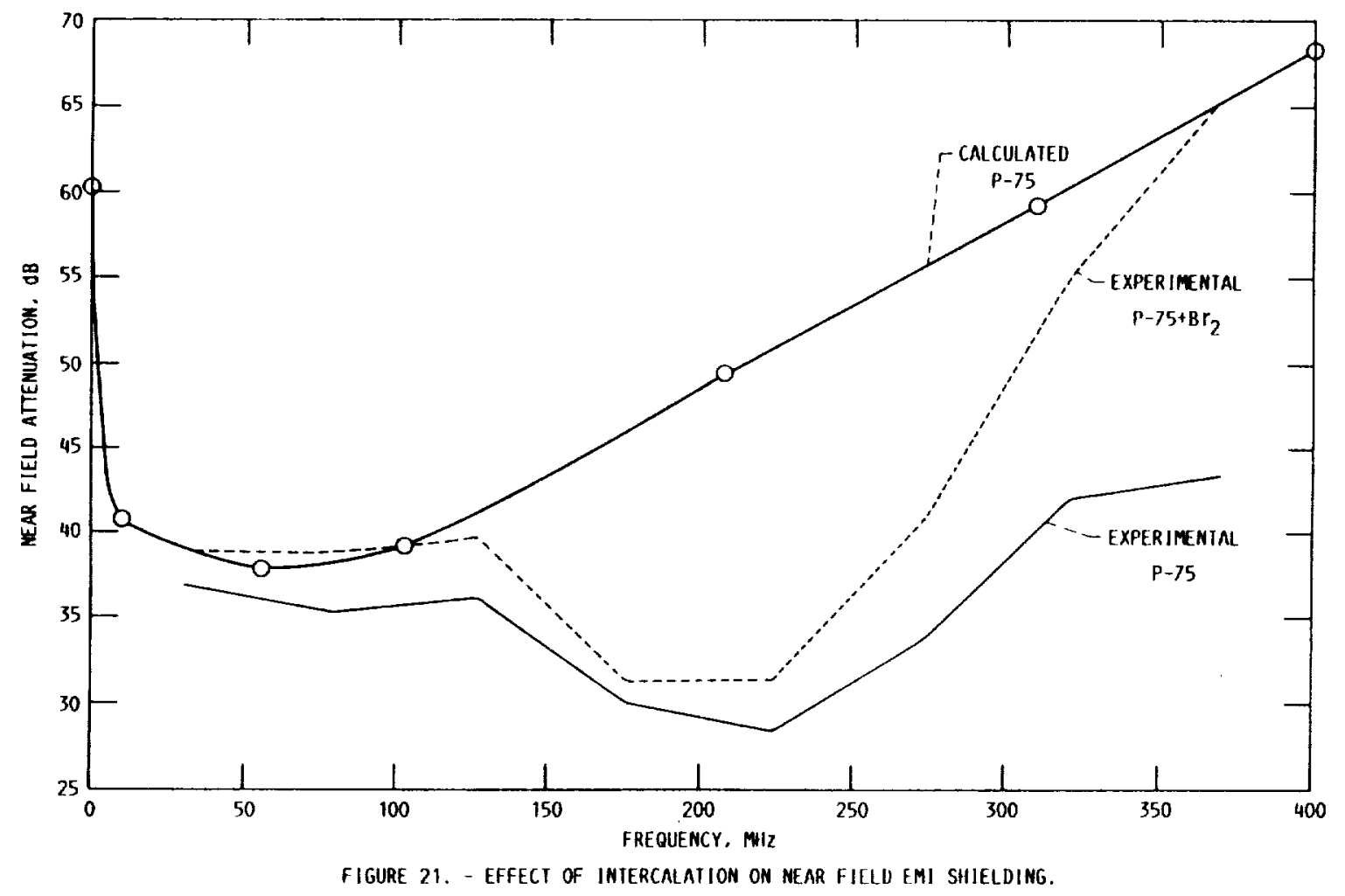




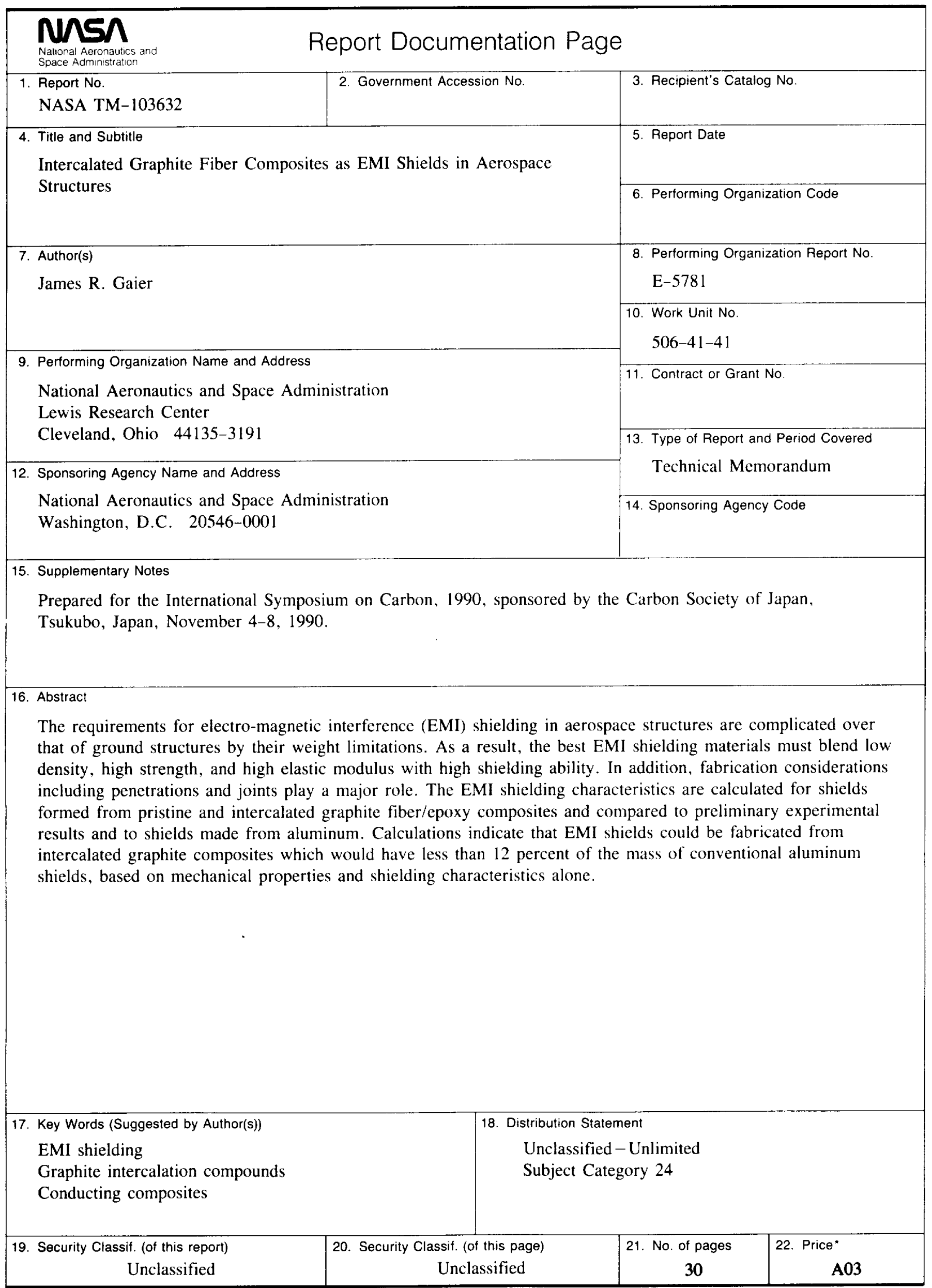



National Aeronautics and Space Administration

Lewis Research Center

Cleveland, Ohio 44135

FOURTH CLASS MAIL

ADDRESS CORRECTION REQUESTED
|||||

Otticlat Businese

Penalty for Privale Use $\$ 300$

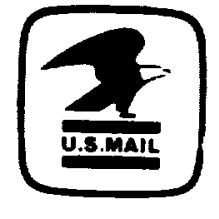

Postage and Fees $F_{i 1}$ ? Nationit Aerionatures and

Smace Admints, tratur in NASA 45 